\title{
Dynamic Chiral PPA-AgNPs Nanocomposites: Aligned Silver Nanoparticles Decorating Helical Polymers
}

Manuel Núñez-Martínez, Sandra Arias, Emilio Quiñoá, Ricardo Riguera, Félix Freire*

Centro Singular de Investigación en Química Biolóxica e Materiais Moleculares (CiQUS) and Departmento de Quimica Orgánica, Universidade de Santiago de Compostela, 15782 Santiago de Compostela, Spain

felix.freire@usc.es

http://www.felixfreire.com

https://www.usc.es/ciqus/es/grupos/nanobiomol

Supporting Information 


\section{Contents}

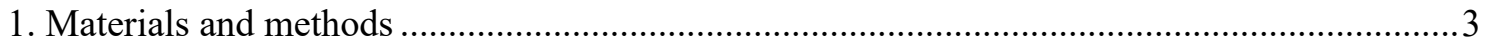

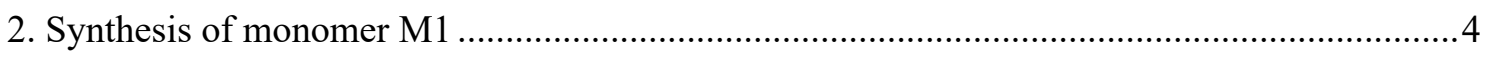

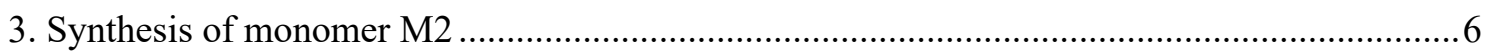

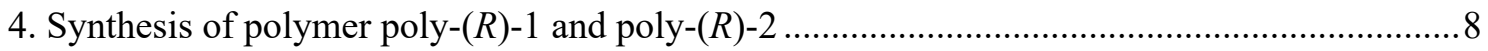

5. CD and UV-Vis studies of poly-(R)-2 with monovalent and divalent metal ions ...................10

6. General procedure for the synthesis of poly-1-AgNPs and poly- $(R)-2-\operatorname{AgNPs} \ldots \ldots \ldots \ldots \ldots \ldots \ldots \ldots . . . . . . . .11$

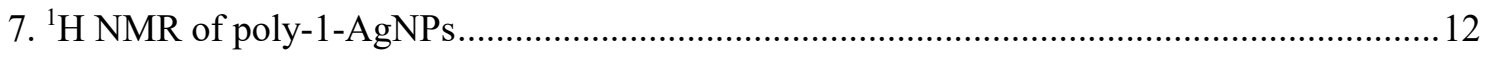

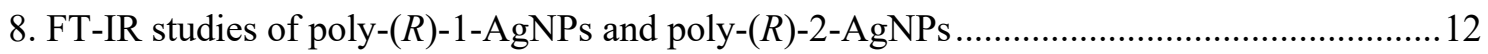

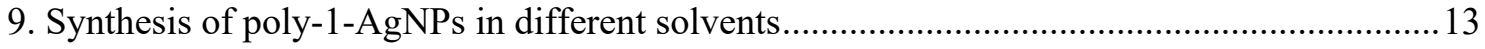

10. CD and UV-Vis studies of poly-1-AgNPs/metal ion interactions ......................................18

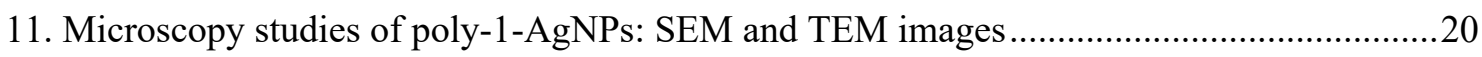

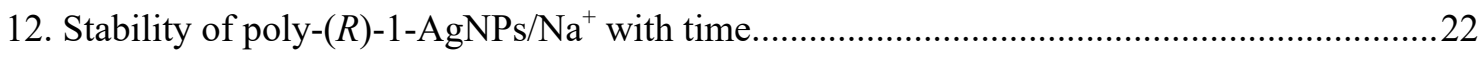

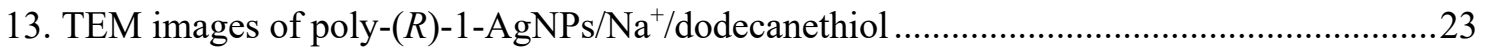

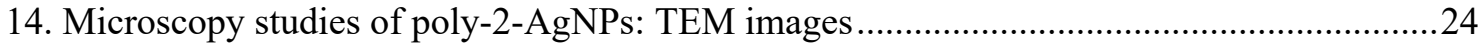

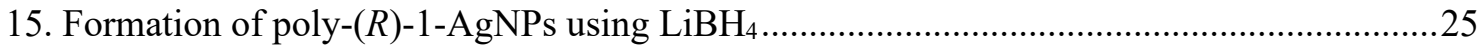

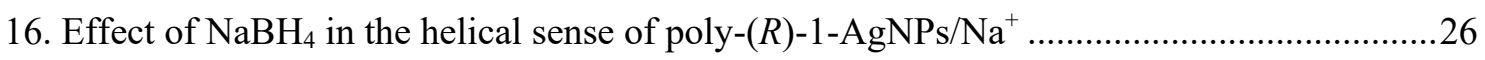

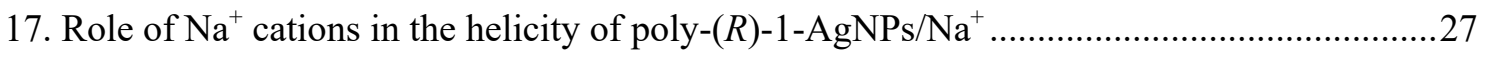

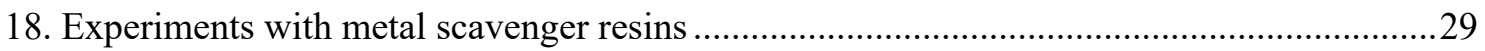

19. Formation of chiral nanospheres using poly- $(R)-1-\operatorname{AgNPs} /$ dodecanethiol and monovalent

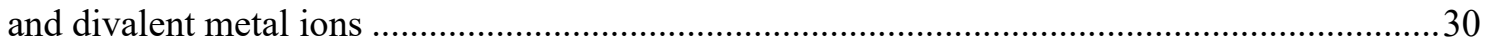

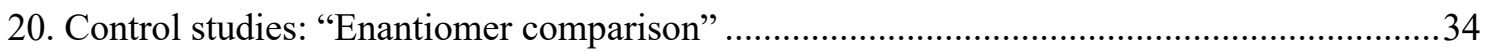

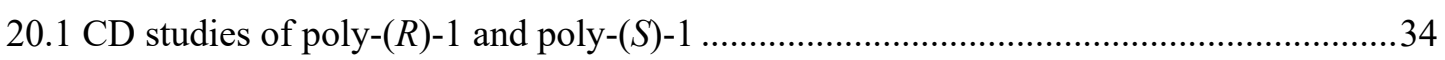

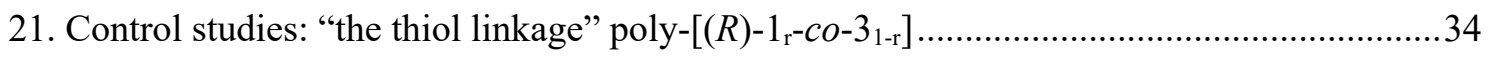

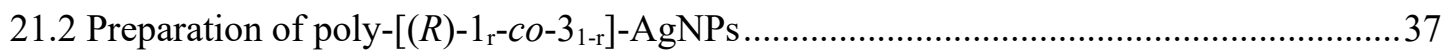

22. Chiral enhancement and reversibility of the process with resins metal scavengers in presence

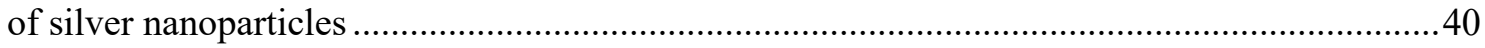

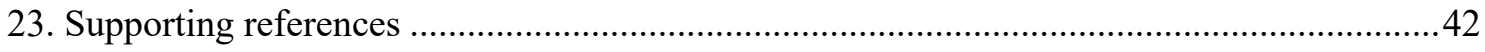




\section{Materials and methods}

Chemicals. Commercially available chemicals have been used as delivered. Solvents were purchased as reagent grade and distilled if necessary. Anhydrous solvents were either purchased as ultra-dry solvent from Acros Organics ${ }^{\circledR}$ or received from solvent purification system. For the coupling and polymerization reactions, dry THF was obtained from MBRAUN SPS 800 solvent purification system. Water was purified by Millipore water purification system. Coupling reagents (2-(7-Aza-1H-benzotriazole-1-yl)-1,1,3,3-tetramethyluronium hexafluorophosphate) (HATU), 1-hydroxy-7-azabenzotriazole (HOAT), 4- ethynylbenzoic acid, and 4-ethynylaniline were purchased from AnaSpec Inc. $(R)$-a-methoxyphenylacetic acid, $(R)$-a-methoxy-atrifluorophenylacetic acid, oxalyl choride, rhodium norbornadiene chloride dimer $\left\{[\mathrm{Rh}(\mathrm{nbd}) \mathrm{Cl}]_{2}\right\}$, diisopropyltriethylamine (DIEA), triethylamine (TEA, 99\%), dodecanethiol, sodium borohydride $\left(\mathrm{NaBH}_{4}\right)$, silver perchlorate $\left(\mathrm{AgClO}_{4}\right)$ and barium perchlorate $\left[\left(\mathrm{Ba}\left(\mathrm{ClO}_{4}\right)_{2}\right]\right.$ a were purchased from Aldrich.

Instrumentations and Characterizations. NMR experiments were carried out in a Varian Inova 300 (300 MHz resonance 1H). Size exclusion chromatography studies were performed on Alliance 2695 HPLC System (Waters) liquid chromatography system equipped with a UV 2489 detector (Waters). The samples were eluted by three Phenogel columns connected to each other with stationary phases of $10^{3}, 10^{4}$ and $10^{5}$ Amstrong and packed with a solid support of a crosslinked styrene and $p$-divinylbenzene copolymer. CD and UV measurements were registered in a Jasco-720 spectropolarimeter and a Jasco-730 spectrophotometer respectively at a nanocomposite concentration of $0.3 \mathrm{mg} \mathrm{mL}^{-1}$. FT-IR measurements were carried out on a Bruker IFS-66v. DLS studies were performed on a Nano-ZS 90 (Malvern) equipped with a HeNe laser $(1=633 \mathrm{~nm})$ under scattering angle of $173^{\circ}$. The samples were maintained at the designed temperature for 5 min before testing. DLS measurements were carried out in all cases at $0.3 \mathrm{mg} \cdot \mathrm{mL}^{-1}$. SEM samples were performed on a LEO-435VP electron microscope. SEM measurements were performed on a LEO-435VP electron microscope equipped with an energy dispersive X-ray (EDX) spectrometer. TEM measurements were performed on a JEOL JEM 2010 and $200 \mathrm{KV}$ as a voltage. To study the nanocomposite, or the nanospheres the same protocol was used. A dispersion of the nanocomposite or the nanospheres at a concentration of $0.3 \mathrm{mg} \mathrm{mL}^{-1}$ was drop casted onto of silicon wafer chip and allowed to dry at $\mathrm{rt}$ for $12 \mathrm{~h}$ for SEM studies, while in case of TEM studies the dispersed materials were drop-casted onto carbon chip and allowed to dry at rt for 12.h. 


\section{Synthesis of monomer M1}
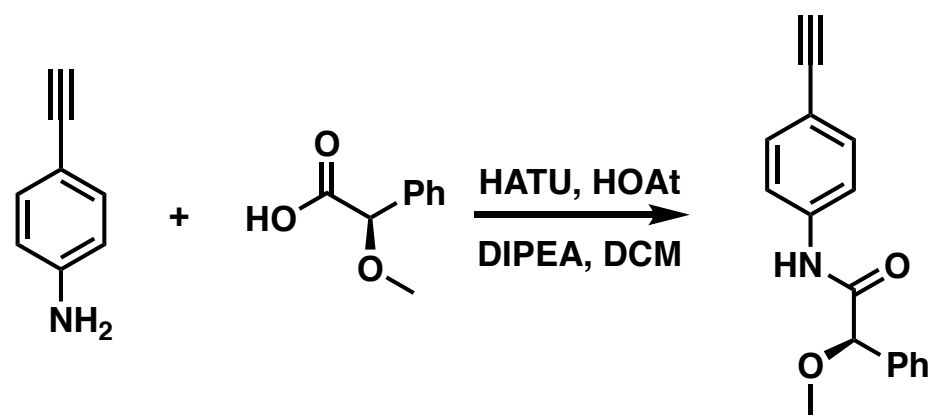

The general procedure of the synthesis of monomer M1 can be found in the reference [S1].

(2-(7-Aza-1H-benzotriazole-1-yl)-1,1,3,3-tetramethyluronium hexafluorophosphate) (HATU, $971 \mathrm{mg}, 2.55 \mathrm{mmol}$ ), 1-hydroxy-7-azabenzotriazole (HOAt, $348 \mathrm{mg}, 2.55 \mathrm{mmol}$ ), (R)$\alpha$-methoxy- $\alpha$-phenylacetic acid ((R)-MPA, $424 \mathrm{mg}, 2.55 \mathrm{mmol})$, disiisopropyehtylamine (DIPEA) $(330 \mu \mathrm{L}, 2.55 \mathrm{mmol})$ were dissolved in $\mathrm{CH}_{2} \mathrm{Cl}_{2}$ and the mixture was stirred $15 \mathrm{~min}$ to activate the acid. Then, 4-ethynilaniline $(250 \mathrm{mg}, 2.12 \mathrm{mmol})$ was added and the mixture was stirred $24 \mathrm{~h}$. The mixture was washed twice with $\mathrm{HCl} 1 \mathrm{M}$, next with saturated $\mathrm{NaHCO}_{3}$ solution (twice) and finally with saturated $\mathrm{NaCl}$ solution. The crude was chromatographed on silica gel (70-230 mesh) with hexane/ethyl acetate (7/3) as eluent (75\% of yield).

\section{Spectroscopic data:}

${ }^{1} \mathrm{H}$ NMR (300 MHz, $\mathrm{CDCl}_{3}$ ) $\delta(\mathrm{ppm}): 3.12(\mathrm{~s}, 1 \mathrm{H}), 3.43(\mathrm{~s}, 3 \mathrm{H}), 4.77(\mathrm{~s}, 1 \mathrm{H}), 7.31(\mathrm{~m}, 7 \mathrm{H}), 7.68$ $(\mathrm{d}, 2 \mathrm{H}), 8.66(\mathrm{~s}, 1 \mathrm{H})$.

${ }^{13} \mathrm{C}$ NMR (70 MHz, $\mathrm{CHCl}_{3}$ ) $\delta(\mathrm{ppm}): 57.5,77.0,83.5,83.9,117.9,119.4,127.2,128.8,133.0$, 136.4, 137.9, 168.7 .

$[\alpha]_{D}^{20}=-15\left(10 \mathrm{mg} \mathrm{mL}^{-1}, \mathrm{CHCl}_{3}\right)$. 
<smiles>C#Cc1ccc(NC(=O)C(OC)c2ccccc2)cc1</smiles>
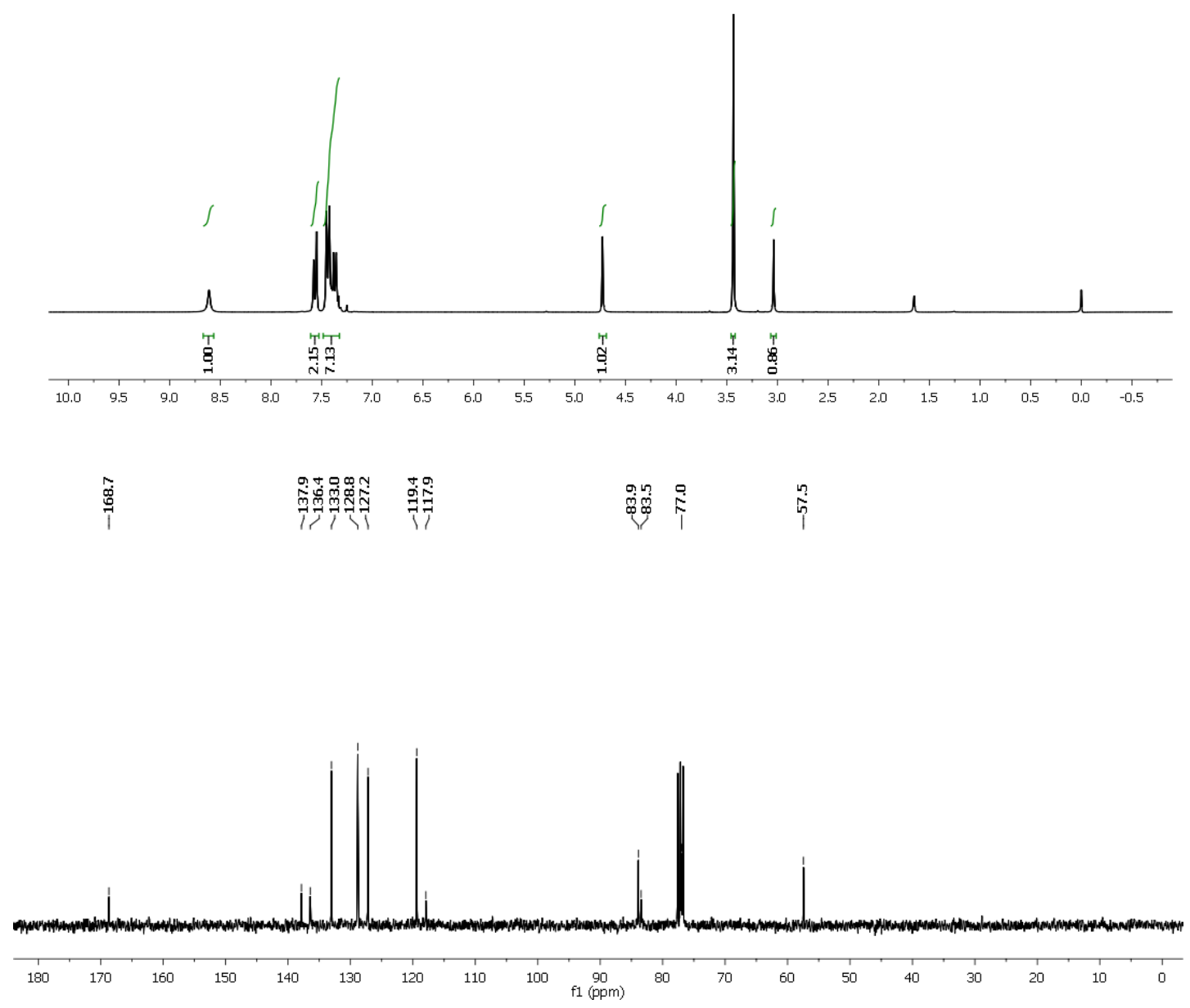

Figure S1. ${ }^{1} \mathrm{H}$ NMR and ${ }^{13} \mathrm{C}$ NMR spectra of monomer $\mathrm{M} 1$ in $\mathrm{CDCl}_{3}$. 


\section{Synthesis of monomer M2}

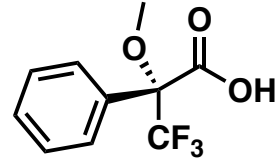

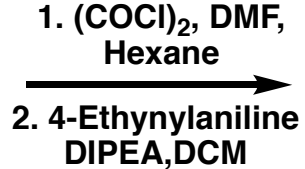

DIPEA,DCM

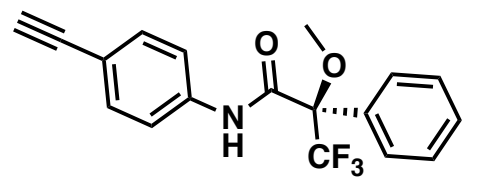

M2

Momomer M2 was prepared according to reference [S2]:

Oxalyl chloride ( $260 \mu \mathrm{L}, 1.4$ equiv) was added dropwise to a solution of $(R)$ - $\alpha$-methoxy$\alpha$-(trifluoromethyl)phenylacetic acid (500 mg, 1.0 equiv) in dry hexane and DMF (300 $\mu \mathrm{L}$ ) at $0^{\circ} \mathrm{C}$ under an Ar atm. After $4 \mathrm{~h}$ stirring at $\mathrm{rt}$, the reaction mixture was filtered, and the solution dried under vacuum to give the acetyl chloride as a colorless oil in quantitative yield.

Next, $(R)$ - $\alpha$-methoxy- $\alpha$-(trifluoromethyl)phenylacetyl chloride was dissolved in DCM (40.0 mL) and diisopropyltriethylamine (DIPEA, $522 \mu \mathrm{L}, 1.4$ equiv) and 4-ethynilaniline (300.0 $\mathrm{mg}, 1.2$ equiv) where added to the solution. The reaction mixture was stirred at rt overnight. The residue was diluted, and the organic solution was washed with $\mathrm{HCl} 1 \mathrm{M}$, saturated $\mathrm{NaHCO}_{3}$ aq. solution and saturated $\mathrm{NaCl}$ aq. solution. The solution was evaporated and the residue was chromatographed on silica gel with hexane-AcOEt (7/3, v/v) as eluent [590 mg M2, 82\% yield of pure product].

\section{Spectroscopic data:}

${ }^{1} \mathrm{H}$ NMR (300 MHz, $\left.\mathrm{CDCl}_{3}\right) \delta(\mathrm{ppm}): 3.06(\mathrm{~s}, 1 \mathrm{H}), 3.49(\mathrm{~s}, 3 \mathrm{H}), 7.41-7.49(\mathrm{~m}, 5 \mathrm{H})$, 7.55-7.59 (m, 4H), 8.61 (broad s, 1H).

${ }^{13} \mathrm{C}$ NMR $\left(70 \mathrm{MHz}, \mathrm{CDCl}_{3}\right) \delta(\mathrm{ppm}): 55.2,77.1,83.1,118.6,119.5,127.7,128.8,129.8,131.9$, $133.0,137.1,164.3$.

${ }^{19} \mathrm{~F}$ NMR (282.24 MHz, $\left.\mathrm{CDCl}_{3}\right) \delta(\mathrm{ppm}):-68.57$.

$[\alpha]_{D}^{20}=+65\left(15 \mathrm{mg} \mathrm{mL}^{-1}, \mathrm{CHCl}_{3}\right)$ 

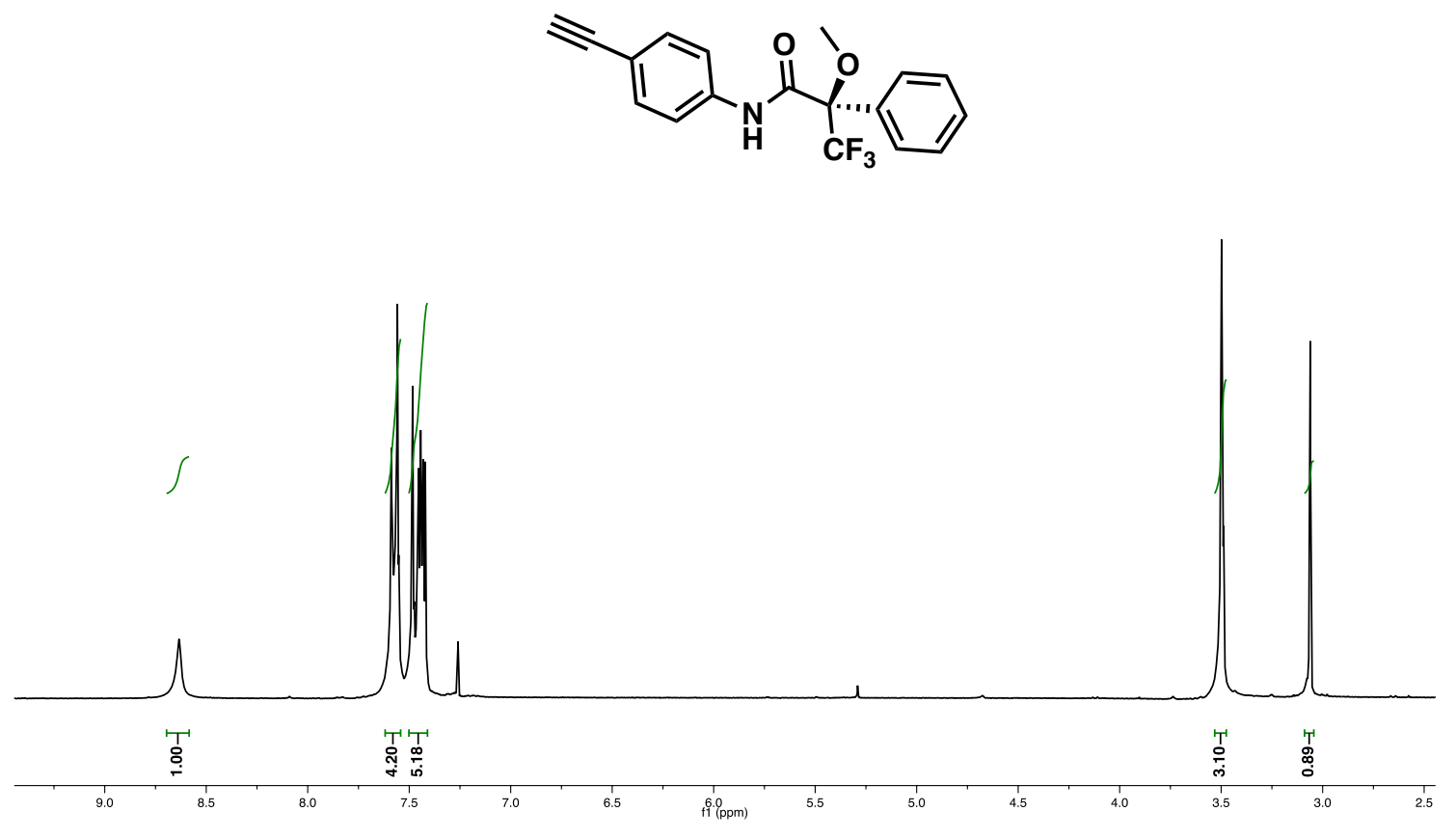

Figure S2. ${ }^{1} \mathrm{H}$ NMR of monomer $\mathrm{M} 2$ in $\mathrm{CDCl}_{3}$.
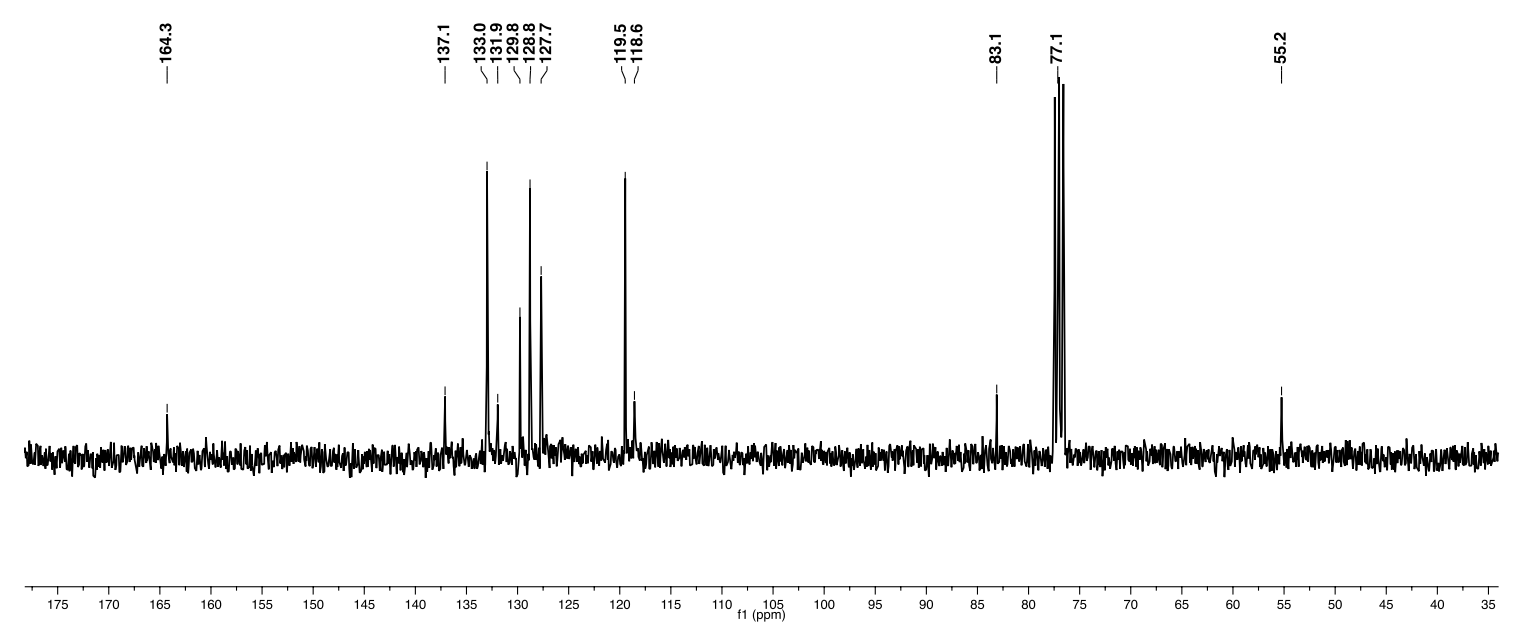

Figure S3. ${ }^{13} \mathrm{C} \mathrm{NMR}$ of monomer $\mathrm{M} 2$ in $\mathrm{CDCl}_{3}$.

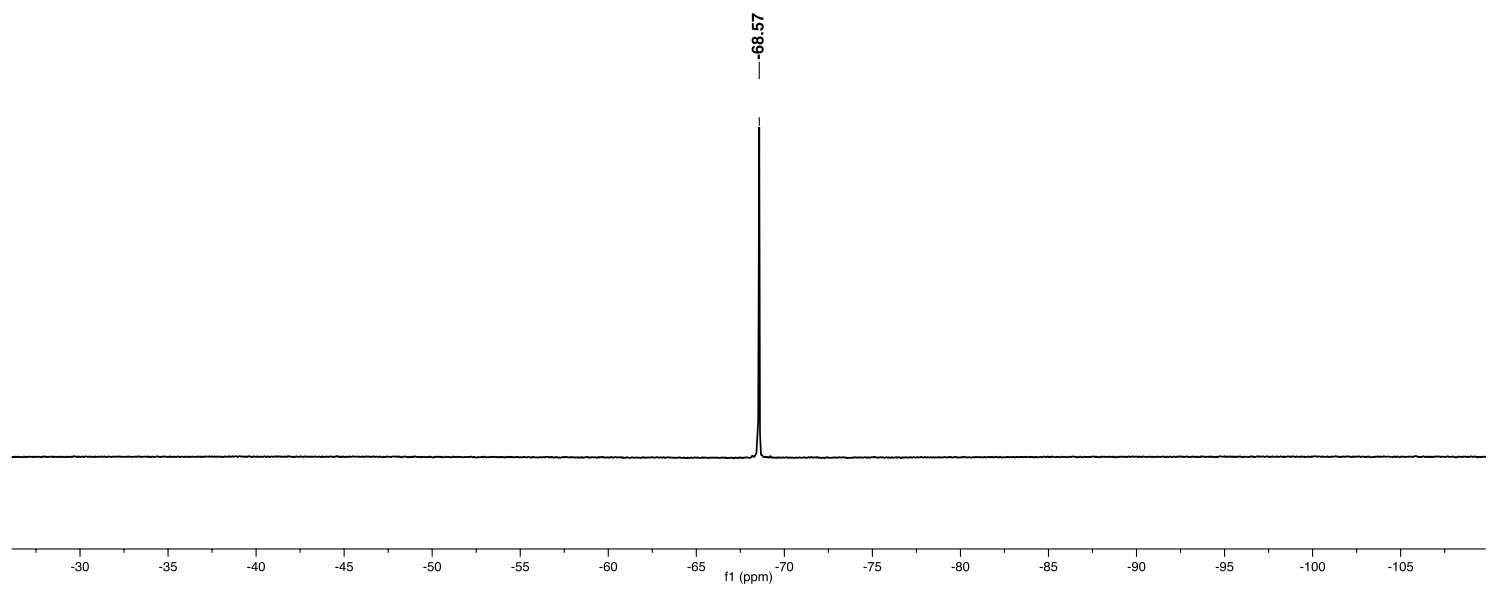

Figure S4. ${ }^{19} \mathrm{~F}$ NMR of monomer $\mathrm{M} 2$ in $\mathrm{CDCl}_{3}$.

7 


\section{Synthesis of polymer poly-(R)-1 and poly- $(R)-2$}

- Synthesis of poly- $(R)-1$

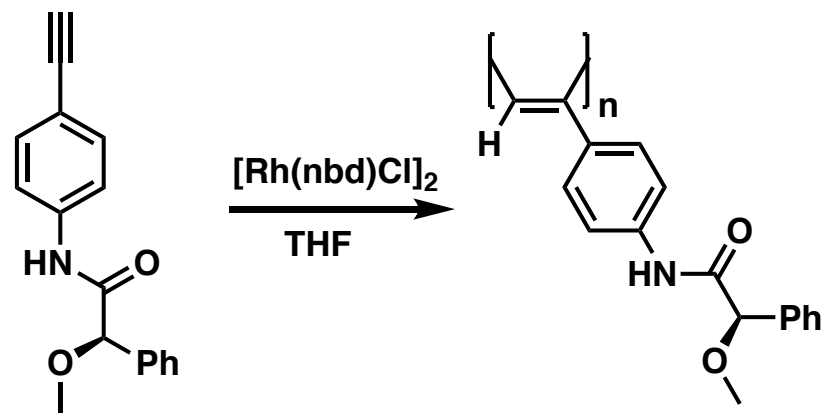

The general procedure for the synthesis of poly- $(R)-\mathbf{1}$ and poly- $(R)-\mathbf{2}$ can be found in references [S1] and [S2].

The reaction flask (sealed ample) was dried under vacuum and Ar flushed for three times before the corresponding monomer M1 (100 mg) was added as a solid. Then, the flask was dried with a vacuum line and flushed with Ar (three times). Dry THF $(0.75 \mathrm{~mL})$ was added with a syringe and $\mathrm{Et}_{3} \mathrm{~N}$ dropwise. A solution of catalyst, $[\mathrm{Rh}(\mathrm{nbd}) \mathrm{Cl}]_{2}(1.70 \mathrm{mg})$ was added at $30^{\circ} \mathrm{C}$. The reaction mixture was stirred at $30^{\circ} \mathrm{C}$ for $24 \mathrm{~h}$. The resulting polymer was diluted in $\mathrm{CH}_{2} \mathrm{Cl}_{2}$ and precipitated in a large amount of $\mathrm{MeOH}$, centrifugated twice and reprecipitated using hexane and centrifugated again ( $90 \%$ of yield).

GPC data of poly-(R)-1: $\mathrm{M}_{\mathrm{n}}: 65563, \mathrm{M}_{\mathrm{w}}: 150744, \mathrm{M}_{\mathrm{p}}: 150264, \mathrm{M}_{\mathrm{z}}: 273851$, PDI: 2.29 .

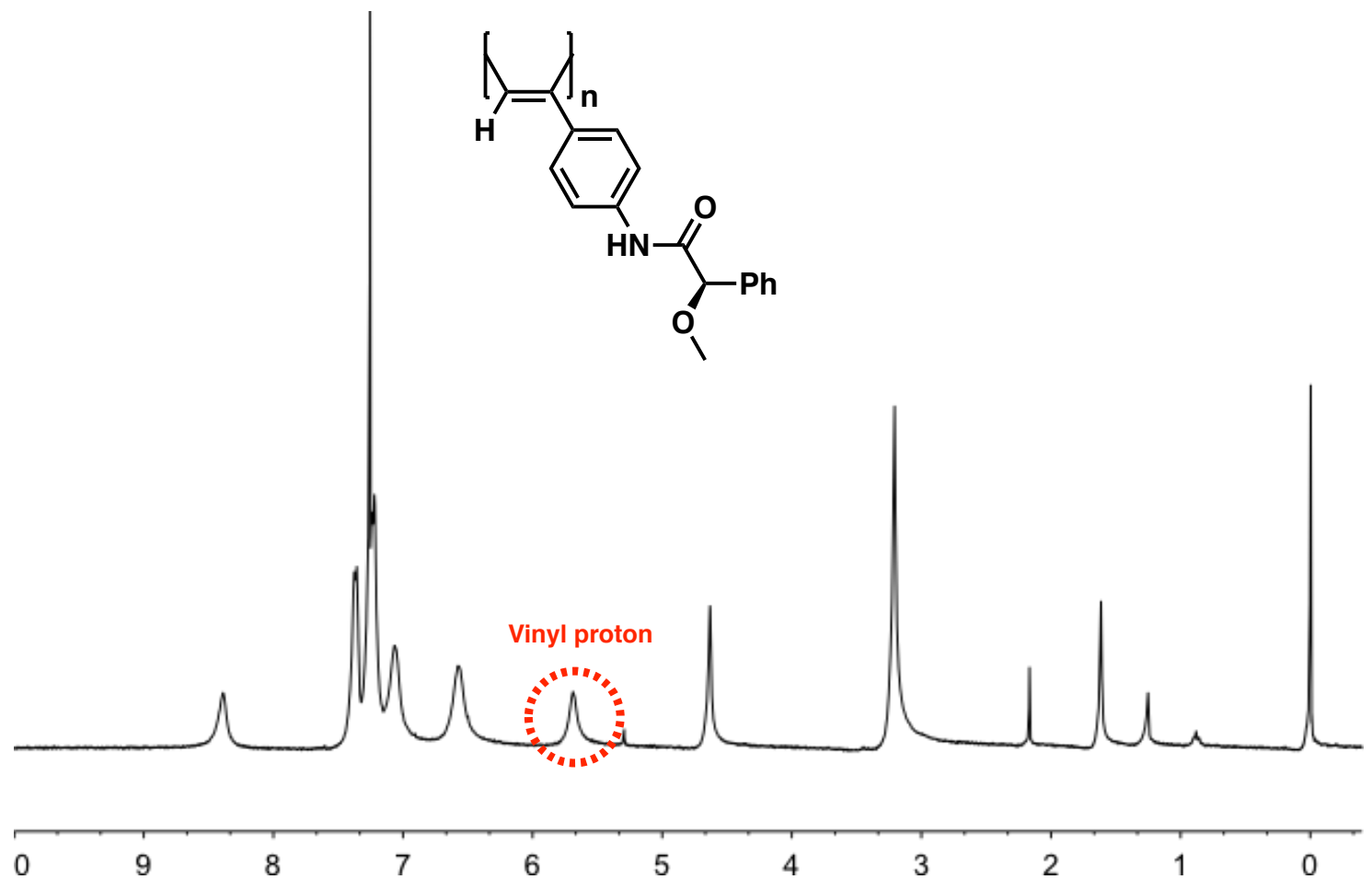

Figure S5. ${ }^{1} \mathrm{H}$ NMR spectrum of poly- $(R)-1$ in $\mathrm{CDCl}_{3}$. 
- Synthesis of poly- $(R)-2$

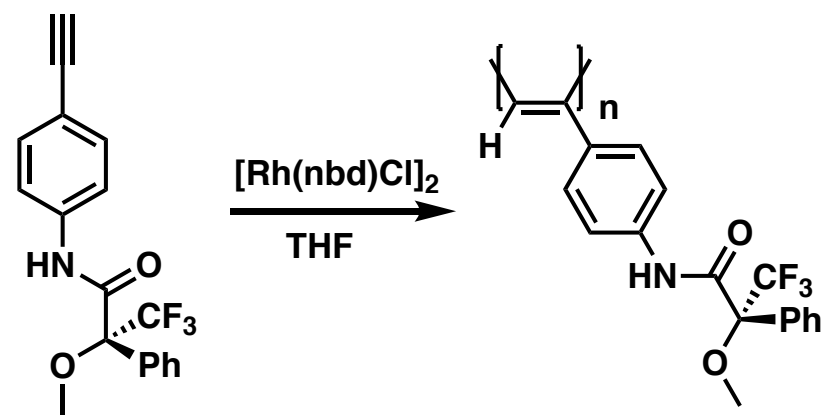

The reaction flask (sealed ample) was dried under vacuum and Ar flushed for three times before the corresponding monomer M2 (75 mg) was added as a solid. Then, the flask was dried with a vacuum line and flushed with Ar (three times). Dry THF $(0.5 \mathrm{~mL})$ was added with a syringe and $\mathrm{Et}_{3} \mathrm{~N}$ dropwise. A solution of catalyst, $\left.[\mathrm{Rh}(\mathrm{nbd}) \mathrm{Cl}]_{2}(1.15 \mathrm{mg})\right]$ was added at $30^{\circ} \mathrm{C}$. The reaction mixture was stirred at $30^{\circ} \mathrm{C}$ for $24 \mathrm{~h}$. The resulting polymer was diluted in $\mathrm{CHCl}_{2}$ and precipitated in a large amount of $\mathrm{MeOH}$, centrifugated twice and reprecipitated using hexane and centrifugated again ( $87 \%$ of yield).

GPC data of poly-(R)-2: $\mathrm{M}_{\mathrm{n}}: 84737, \mathrm{M}_{\mathrm{w}}: 178058, \mathrm{M}_{\mathrm{p}}: 182446, \mathrm{M}_{\mathrm{z}}: 342353$, PDI: 2.10
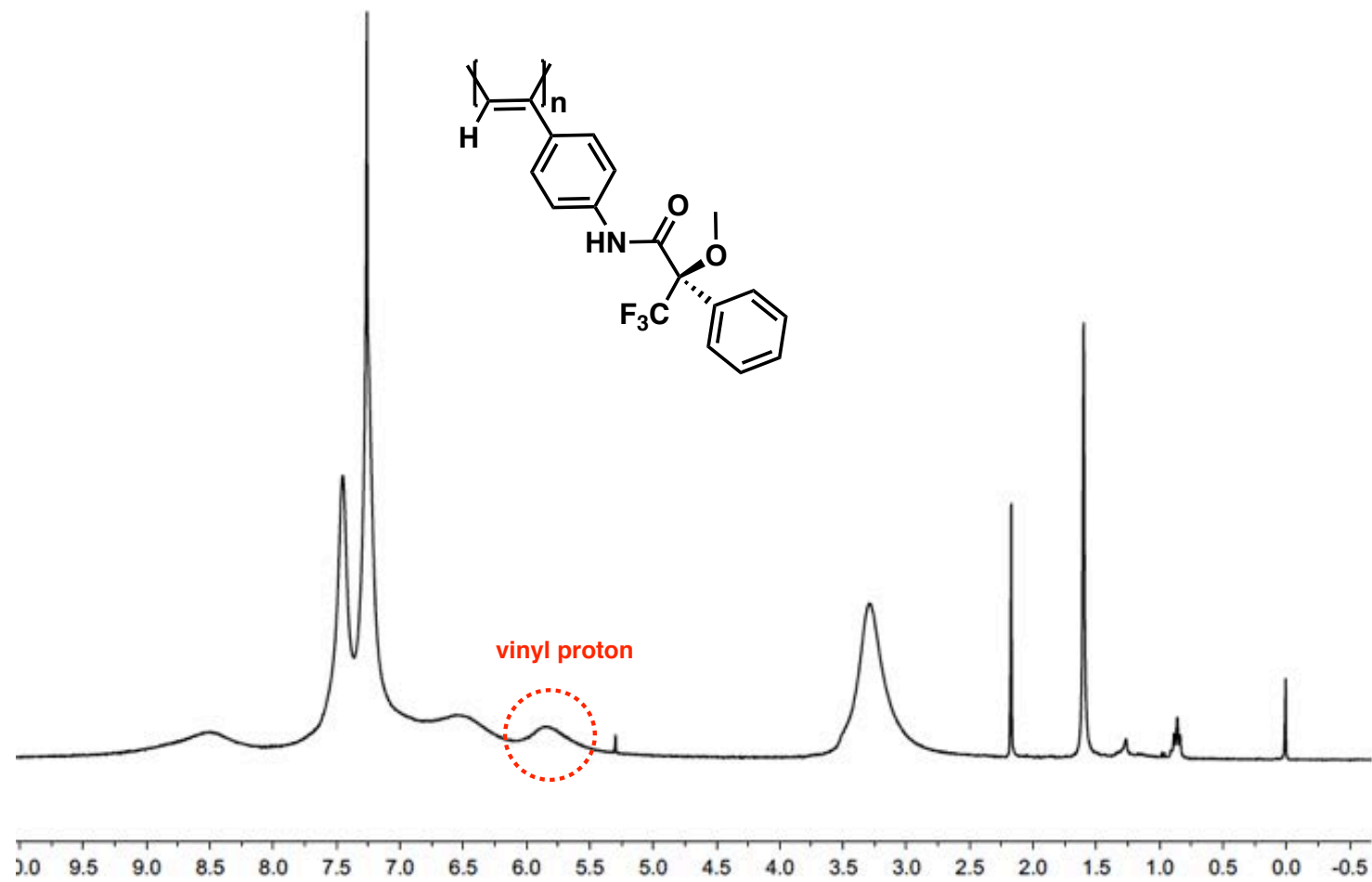

Figure S6. ${ }^{1} \mathrm{H}$ NMR spectrum of poly- $(R)-2$ in $\mathrm{CDCl}_{3}$. 


\section{CD and UV-Vis studies of poly-(R)-2 with monovalent and divalent metal ions}

$\mathrm{CD}$ and $\mathrm{UV}-\mathrm{Vis}$ studies were performed with a solution of poly- $(R)-2$ in $\mathrm{CHCl}_{3}(0.3 \mathrm{mg}$ $\left.\mathrm{mL}^{-1}\right)$ using different amounts of $\mathrm{AgClO}_{4}\left(10 \mathrm{mg} \mathrm{mL}^{-1}, \mathrm{MeOH}\right)$ as source of monovalent metal ion and $\mathrm{Ba}\left(\mathrm{ClO}_{4}\right)_{2}\left(10 \mathrm{mg} \mathrm{mL}^{-1}, \mathrm{MeOH}\right)$ as source of divalent metal ion.

It was observed that the additions of $\mathrm{Ag}^{+}$and $\mathrm{Ba}^{2+}$ ions to poly- $(R)-2$ do not promote a helical inversion preserving the same helical sense in poly- $(R)-\mathbf{2}$.

Moreover, UV-Vis experiments have shown a bathochromic effect after addition of 0.5 equiv of $\mathrm{Ag}^{+}\left(10 \mathrm{mg} \mathrm{mL}^{-1}, \mathrm{MeOH}\right)$ ions to poly- $(R)-2\left(0.3 \mathrm{mg} \mathrm{mL}^{-1}, \mathrm{CHCl}_{3}\right)$.
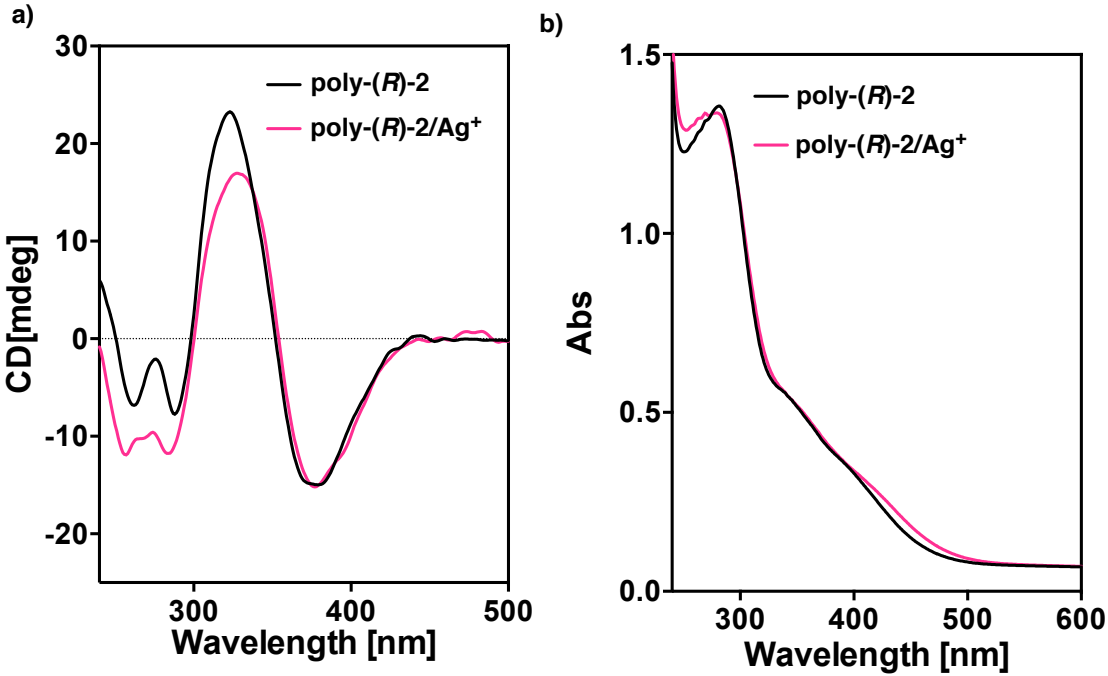

Figure S7. a) CD studies of poly- $(R)-2$ and poly- $(R)-2 / \mathrm{Ag}^{+}$complex. b) UV-Vis studies of poly- $(R)-2$ and poly- $(R)-\mathbf{2} / \mathrm{Ag}^{+}$complex.
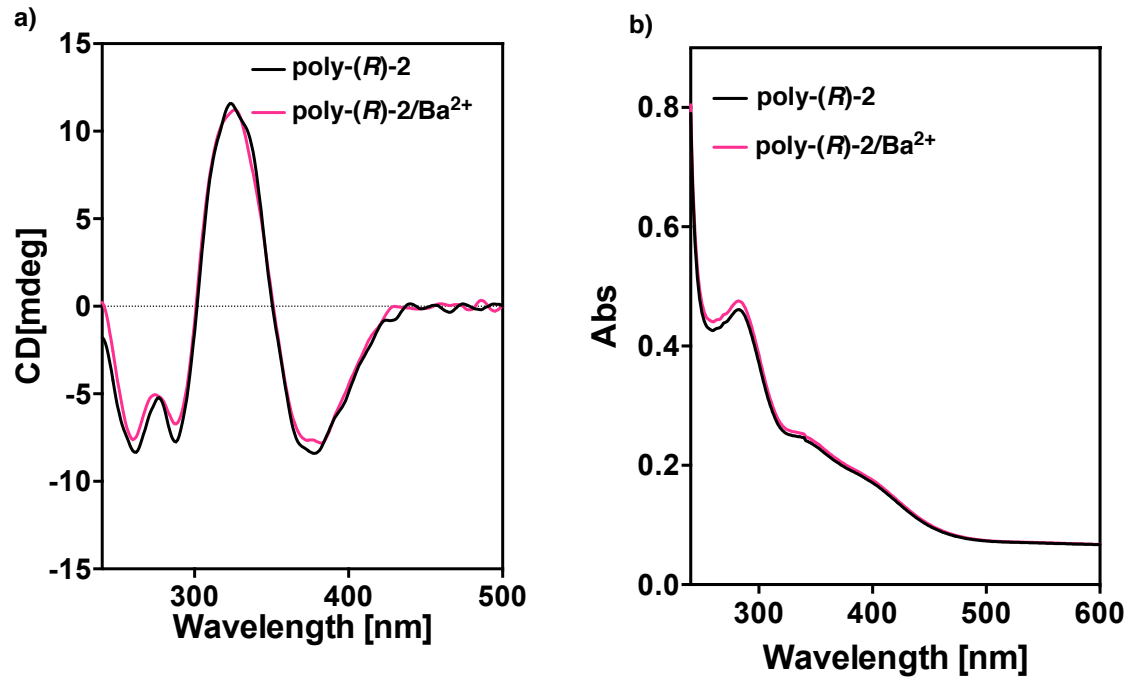

Figure S8. a) CD studies of poly- $(R)-2$ and poly- $(R)-2 / \mathrm{Ba}^{2+}$ complex. b) UV-Vis studies of poly- $(R)-2$ and poly- $(R)-2 / \mathrm{Ba}^{2+}$ complex. 

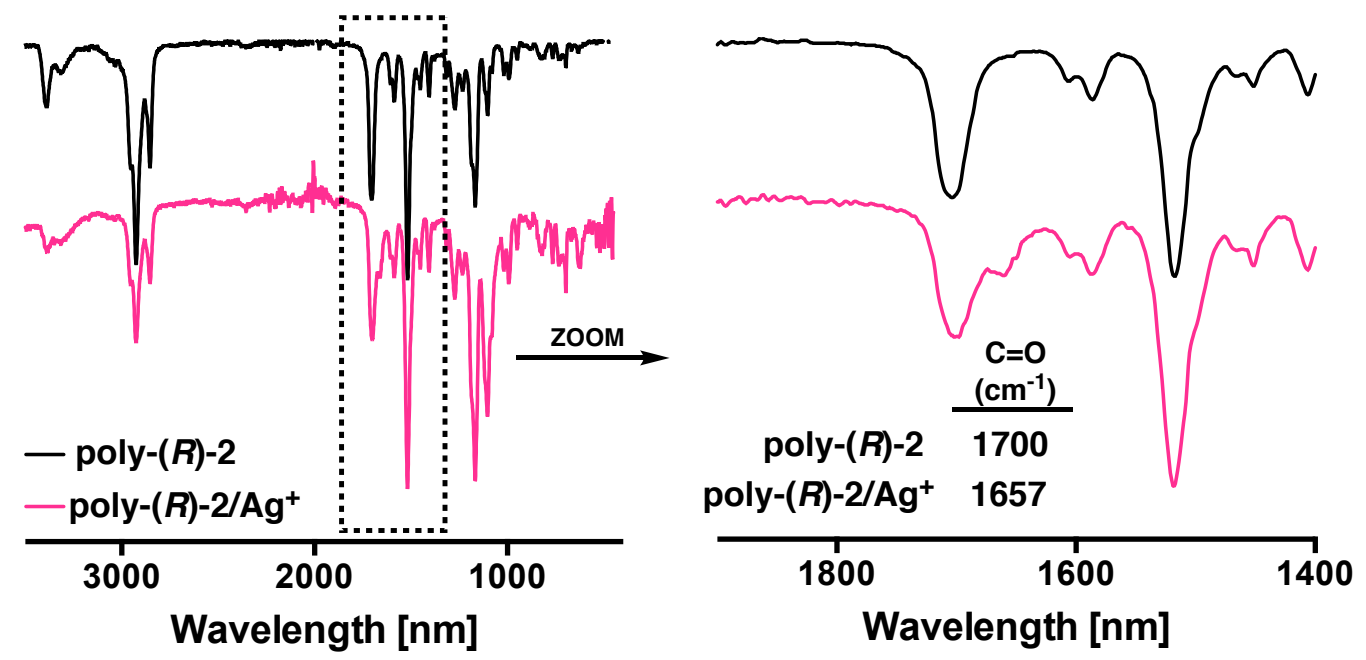

Figure S9. FT-IR studies of poly- $(R)-2$ and poly- $(R)-2 / \mathrm{Ag}^{+}$complex.

\section{General procedure for the synthesis of poly-1-AgNPs and poly-(R)-2-} AgNPs

Poly-(R)-1-AgNPs and poly- $(R)-2-A g N P s$ were prepared according to this procedure. First, all the glassware was washed with aqua regia, Milli $\mathrm{Q}$ water and acetone. The reactions were carried out at $\mathrm{rt}$ and using an Ar atmosphere.

Poly- $(R)-1$ (or poly- $(R)-2)$ was dissolved in $\mathrm{CHCl}_{3}\left(0.3 \mathrm{mg} \mathrm{mL}^{-1}\right)$ and then, $\mathrm{AgClO}_{4}(0.5$ equiv) in $\mathrm{MeOH}$ was added to form the poly- $(R)-1 / \mathrm{Ag}^{+}$complexes. $\mathrm{Next}, \mathrm{NaBH}_{4}(1.0$ equiv, 1.0 $\left.\mathrm{mg} \mathrm{mL} \mathrm{mL}^{-1}, \mathrm{MeOH}\right)$ was added to form AgNPs. Finally, 1-dodecanethiol was added to the dispersion of AgNPs.

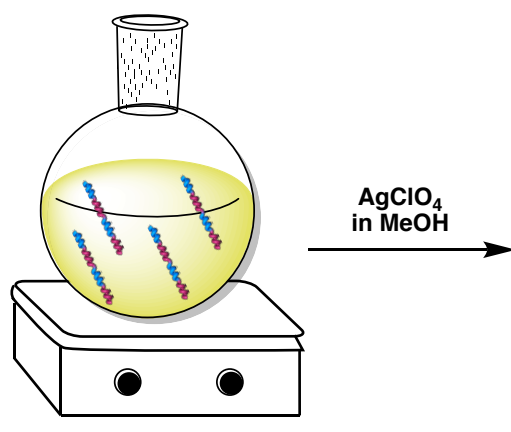

poly-1 in $\mathrm{CHCl}_{3}$

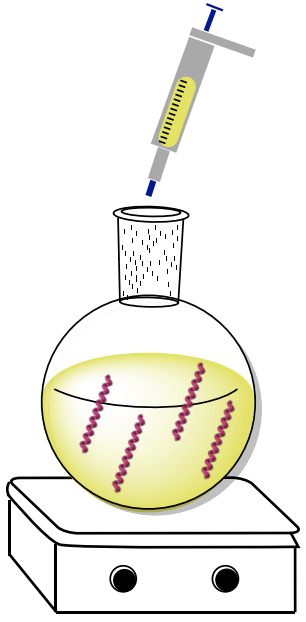

poly-1/Ag+ complex

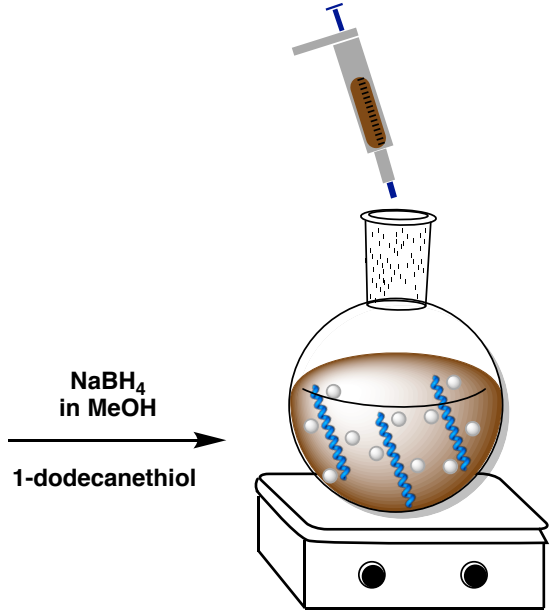

poly-1-AgNPs/Na $+/$ dodecanethiol

Scheme S1. Schematic representation for the synthesis of poly-1-AgNPs or poly- $(R)-2-\operatorname{AgNPs}$ hybrid materials. 


\section{7. ${ }^{1} \mathrm{H}$ NMR of poly-1-AgNPs}

The cis stereoregularity of the poly-1-AgNPs was determined by ${ }^{1} \mathrm{H}$ NMR where the vinylic proton resonance appears at $5.7 \mathrm{ppm}$.

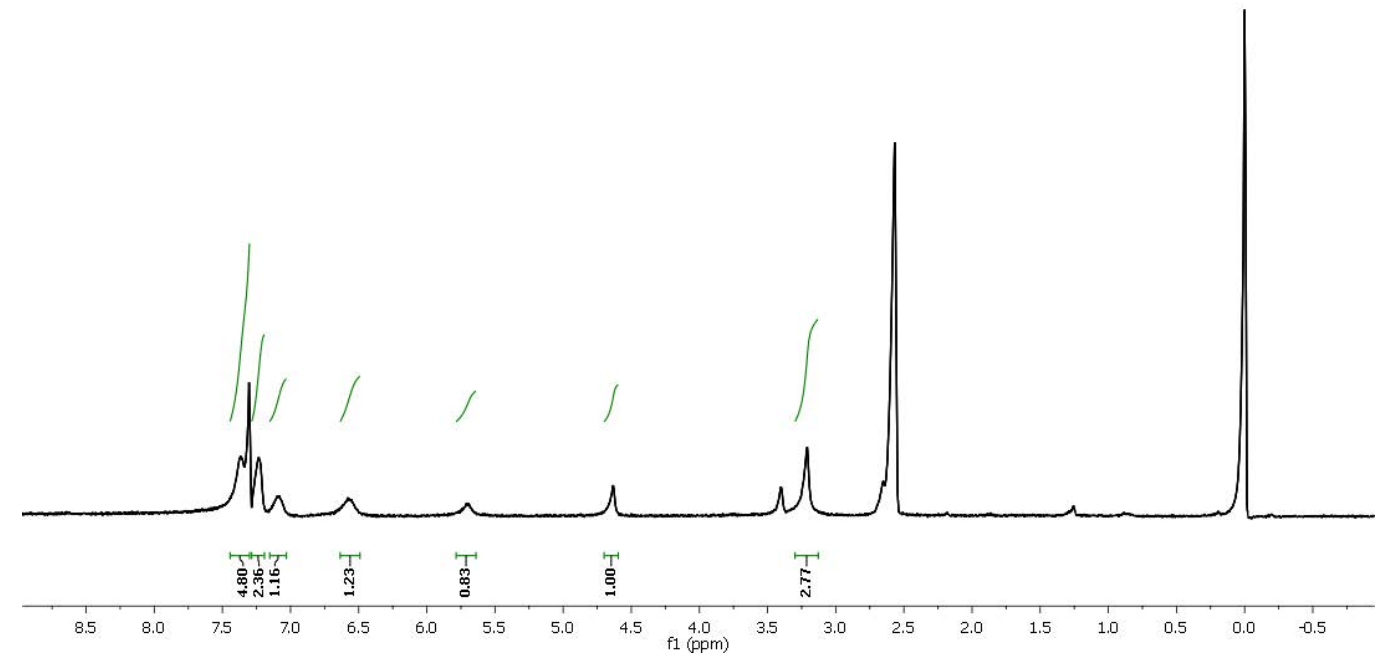

Figure S10. ${ }^{1} \mathrm{H}$ NMR of poly-1-AgNPs in $\mathrm{CDCl}_{3}$.

\section{FT-IR studies of poly-(R)-1-AgNPs and poly-(R)-2-AgNPs}

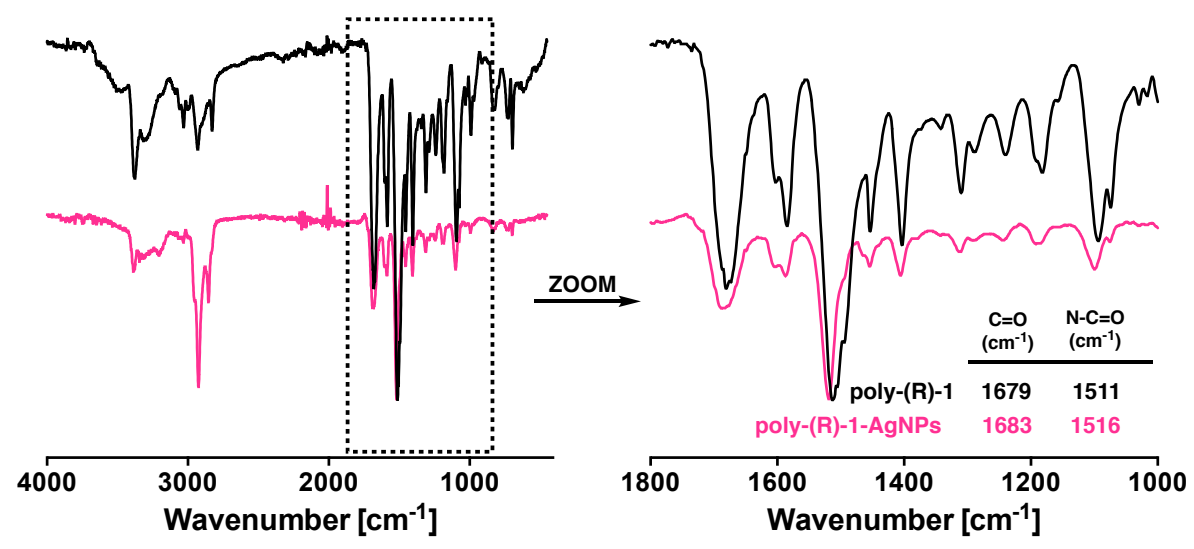

Figure S11. FT-IR spectra of poly-( $(R)-1$ and poly- $(R)-1-\mathrm{AgNPs}$
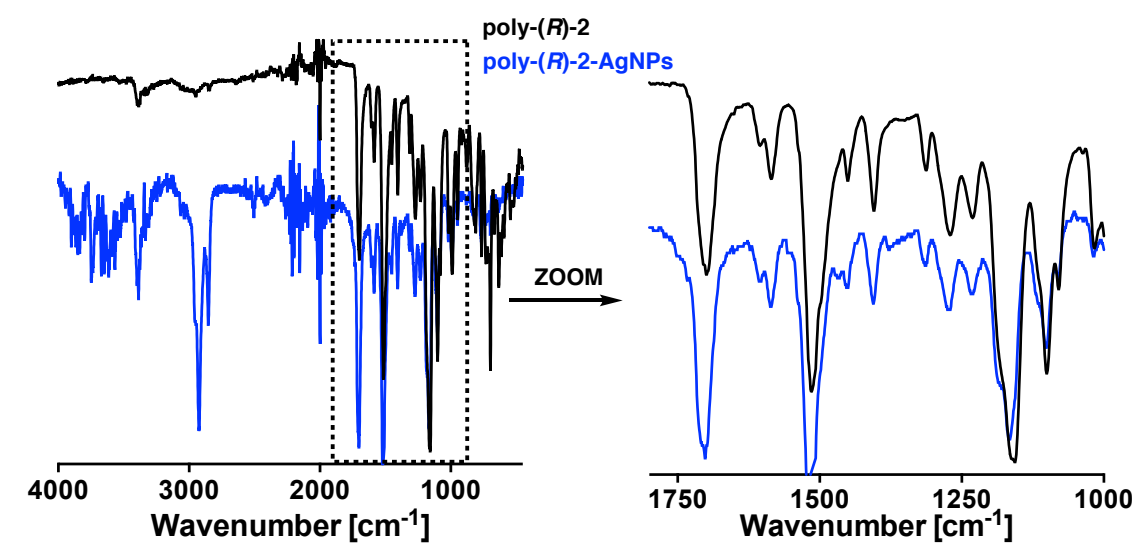

Figure S12. FT-IR spectra of poly-( $R)-2$ and poly-( $(R)-2-A g N P s$ 


\section{Synthesis of poly-1-AgNPs in different solvents}

Following the general procedure, poly-1-AgNPs nanocomposites were prepared using different polar and low-polar solvents.

- Synthesis in THF
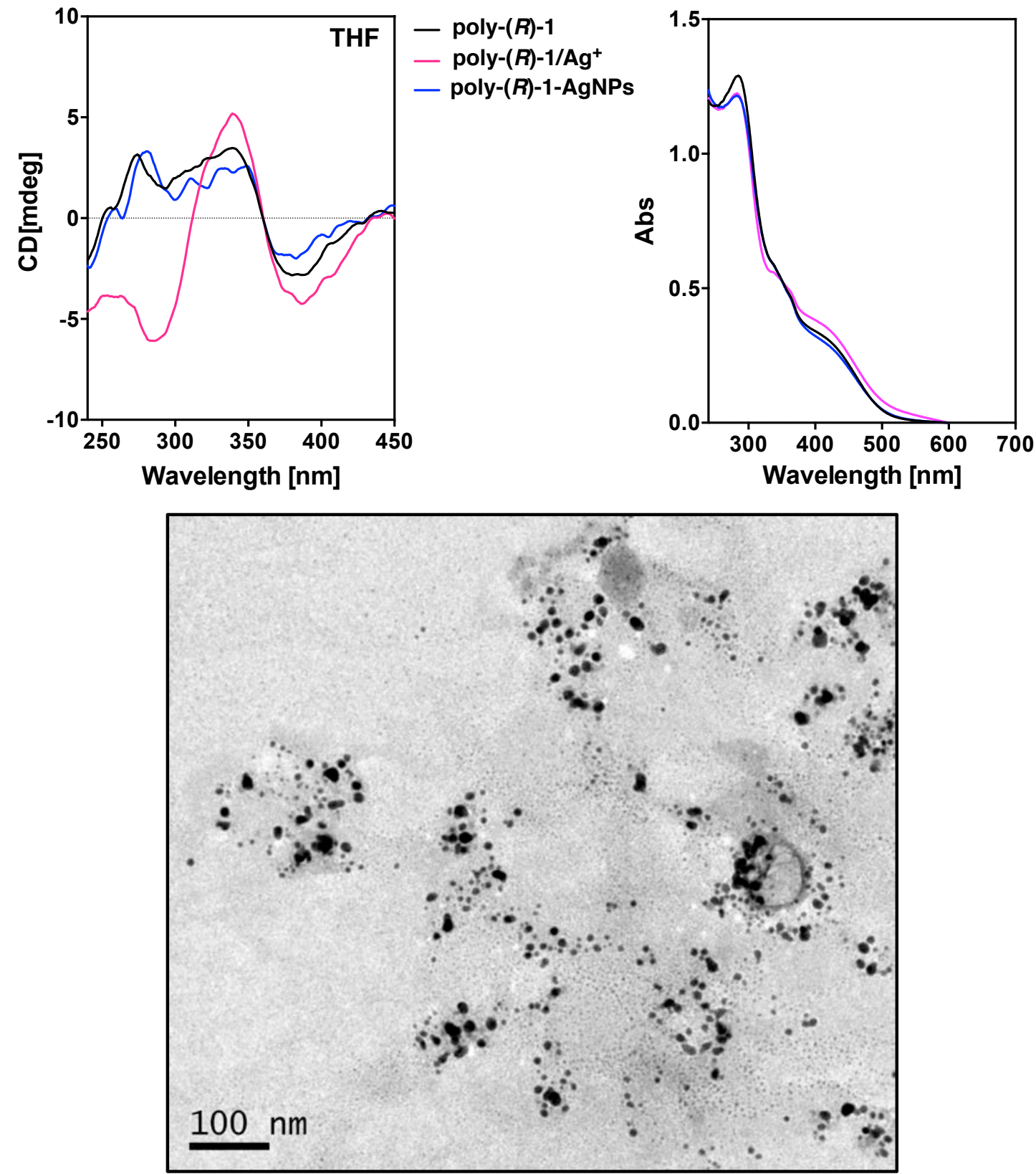

Figure S13. CD, UV-Vis spectra and TEM images of poly-1-AgNPs $\left(0.3 \mathrm{mg} \mathrm{mL}^{-1}\right)$ in THF. 
- Synthesis in dioxane
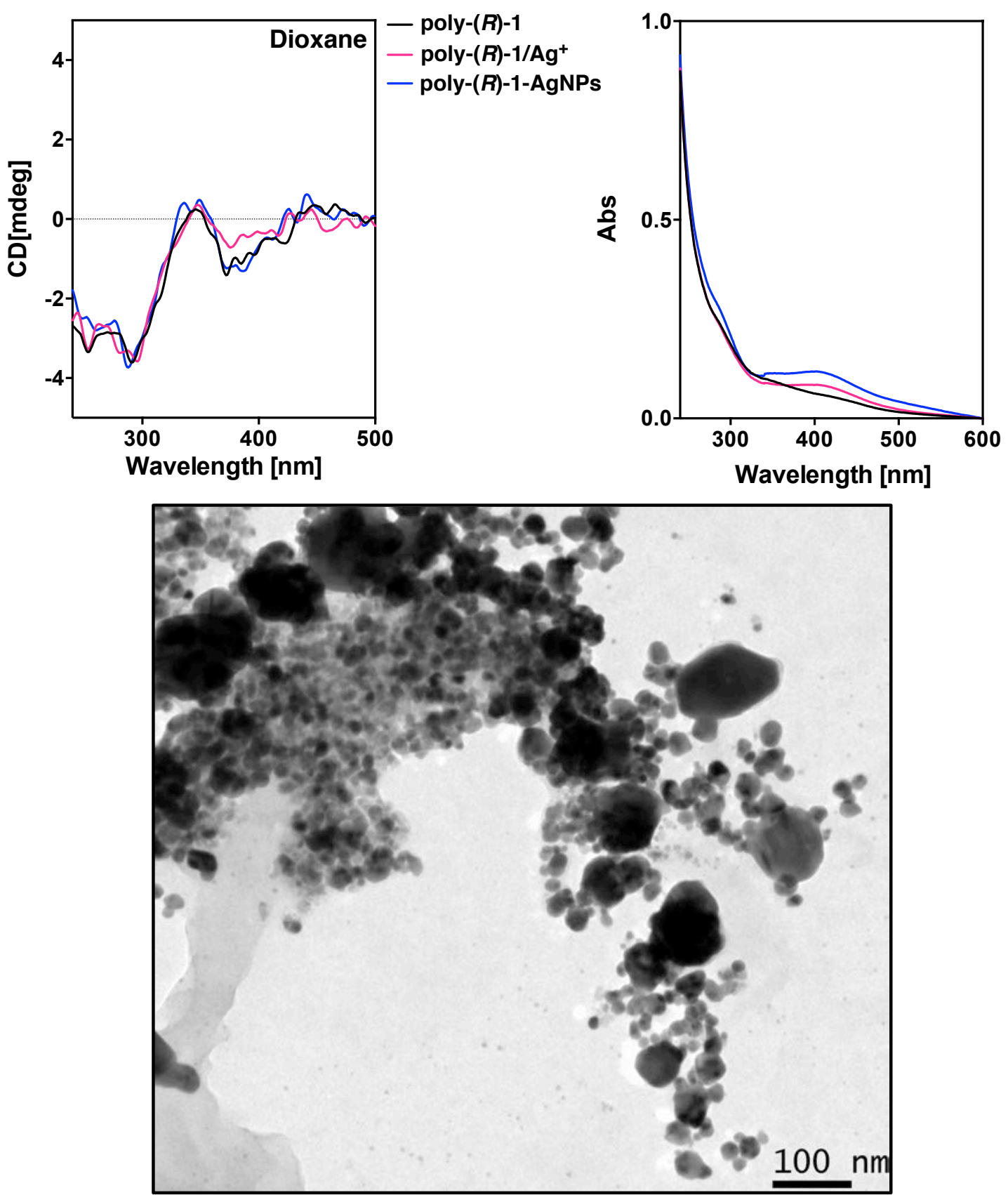

Figure S14. CD, UV-Vis spectra and TEM images of poly-1-AgNPs $\left(0.3 \mathrm{mg} \mathrm{mL}^{-1}\right)$ in dioxane. 
- Synthesis in DMSO

c)
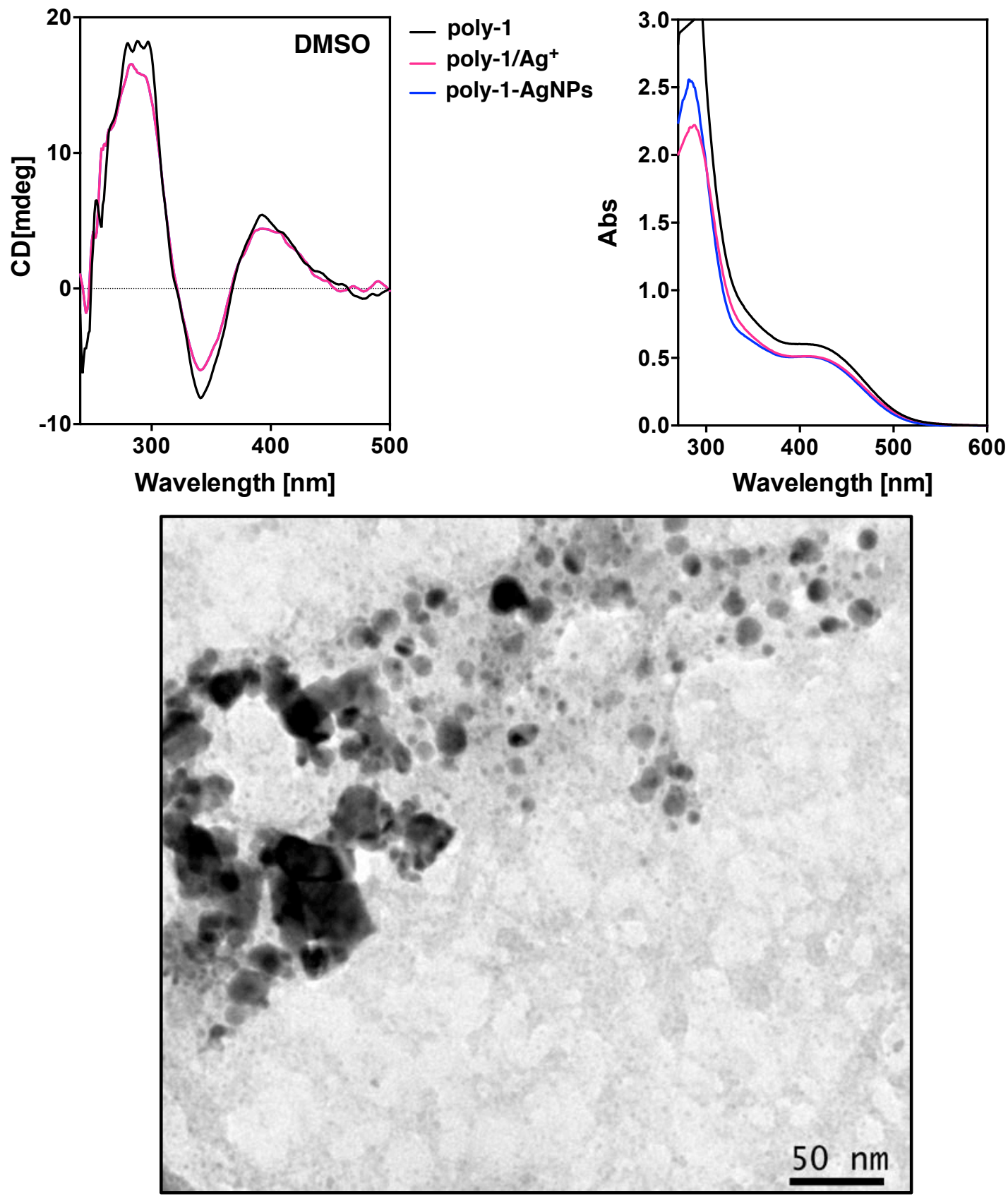

Figure S15. CD, UV-Vis spectra and TEM images of poly-1-AgNPs $\left(0.3 \mathrm{mg} \mathrm{mL}^{-1}\right)$ in DMSO. 
- Synthesis in dichloromethane
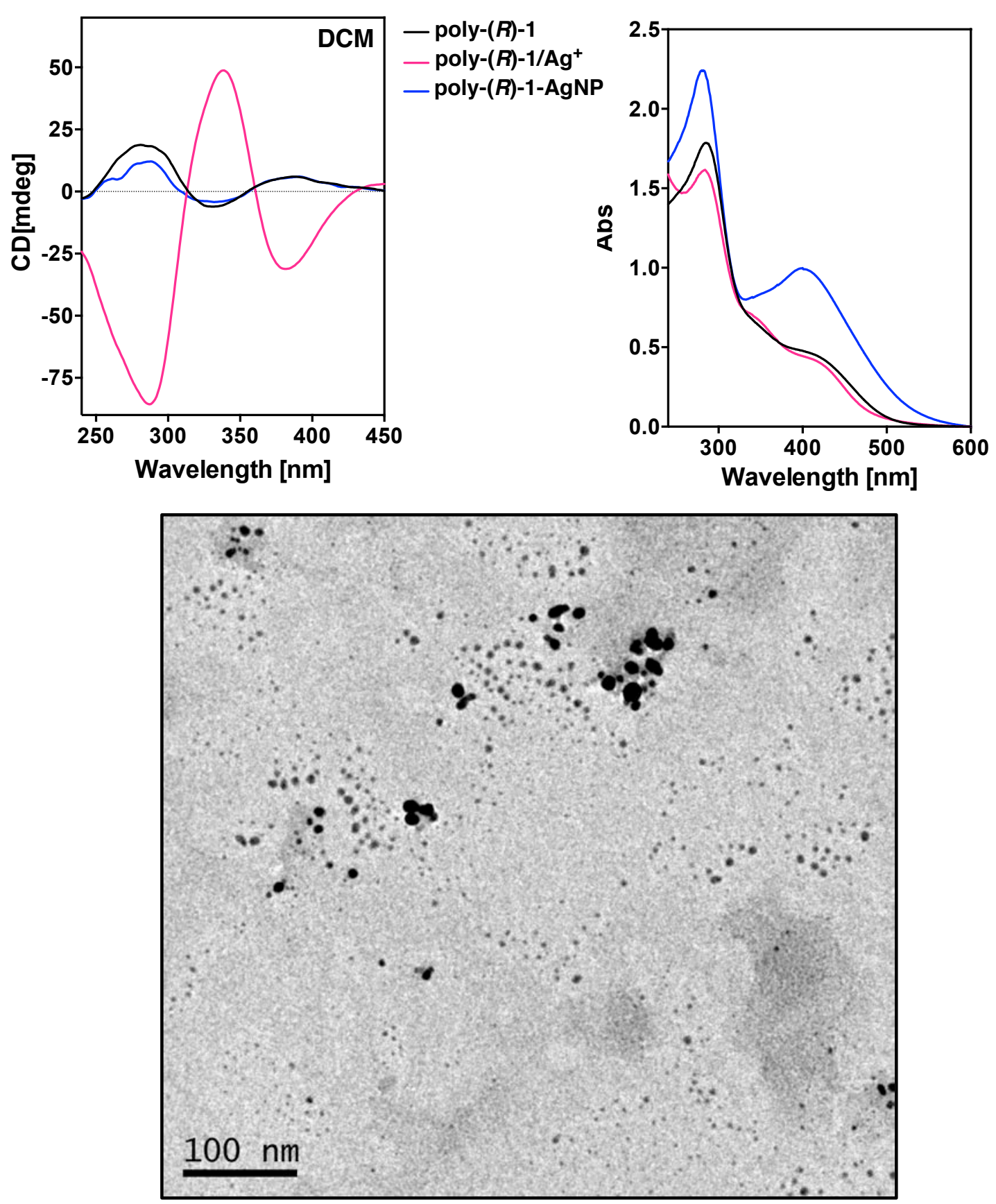

Figure S16. CD, UV-Vis spectra and TEM images of poly-1-AgNPs $\left(0.3 \mathrm{mg} \mathrm{mL}^{-1}\right)$ in DCM. 
- Synthesis in acetone
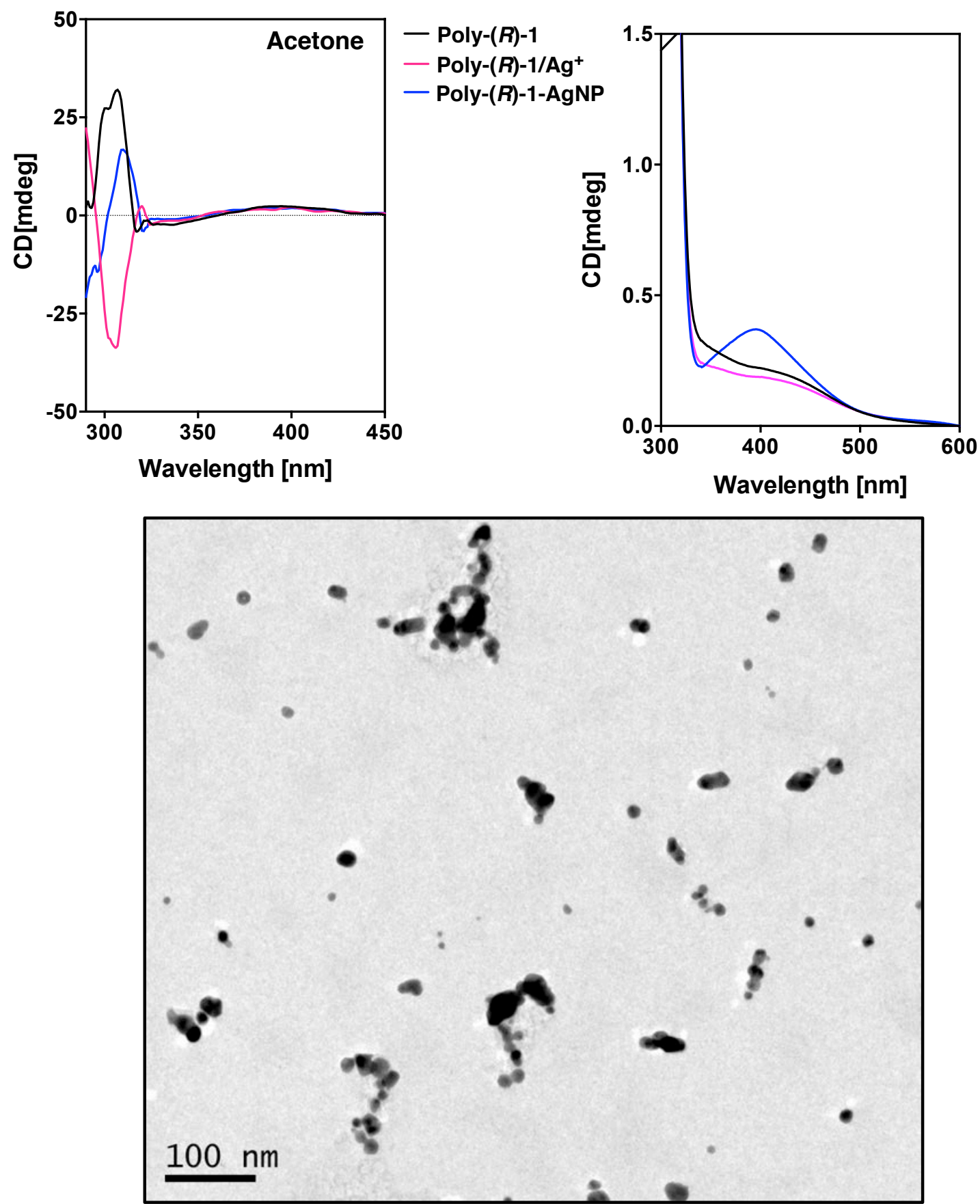

Figure S17. CD, UV-Vis spectra and TEM images of poly-1-AgNPs $\left(0.3 \mathrm{mg} \mathrm{mL}^{-1}\right)$ in acetone. 
- Synthesis in DMF
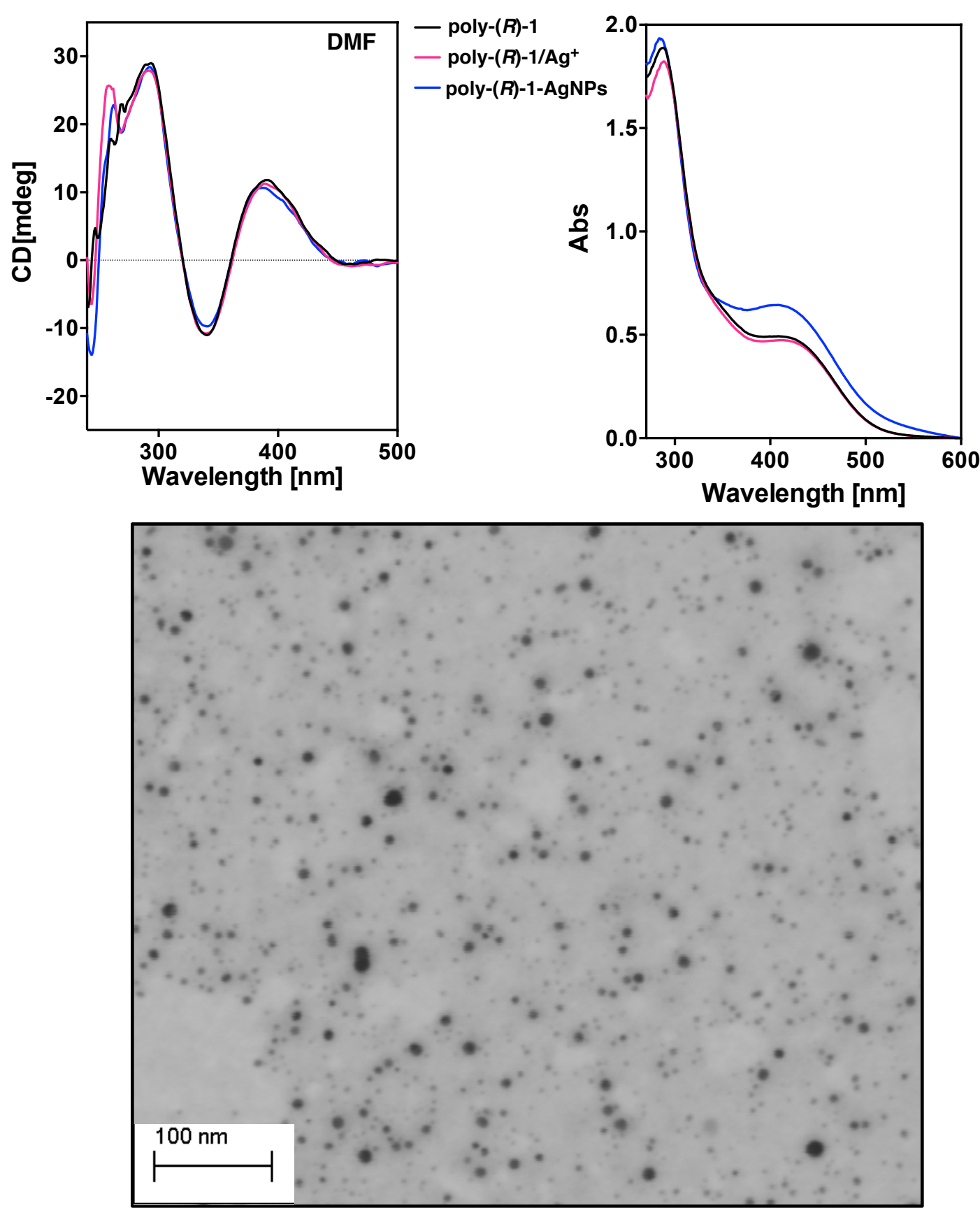

Figure S18. CD, UV-Vis spectra and TEM images of poly-1-AgNPs $\left(0.3 \mathrm{mg} \mathrm{mL}^{-1}\right)$ in DMF.

\section{CD and UV-Vis studies of poly-1-AgNPs/metal ion interactions}

The addition of monovalent metal ions $\left(10.0 \mathrm{mg} \mathrm{mL}^{-1}\right.$ in $\left.\mathrm{MeOH}\right)$ to poly-1-AgNPs $(0.3$ $\mathrm{mg} \mathrm{mL} \mathrm{mL}^{-1}$ in $\left.\mathrm{CHCl}_{3}\right)$ promotes an ap conformation [dihedral angle for $(\mathrm{C}=\mathrm{O}-\mathrm{C}-\mathrm{OMe}) 180^{\circ} \mathrm{ca}$ ] in the pendant group leading to a left-handed helical sense due to the chelation of the monovalent ions to the carbonyl group and the presence of $\mathrm{M}^{+} \square \pi \square$ interaction. 

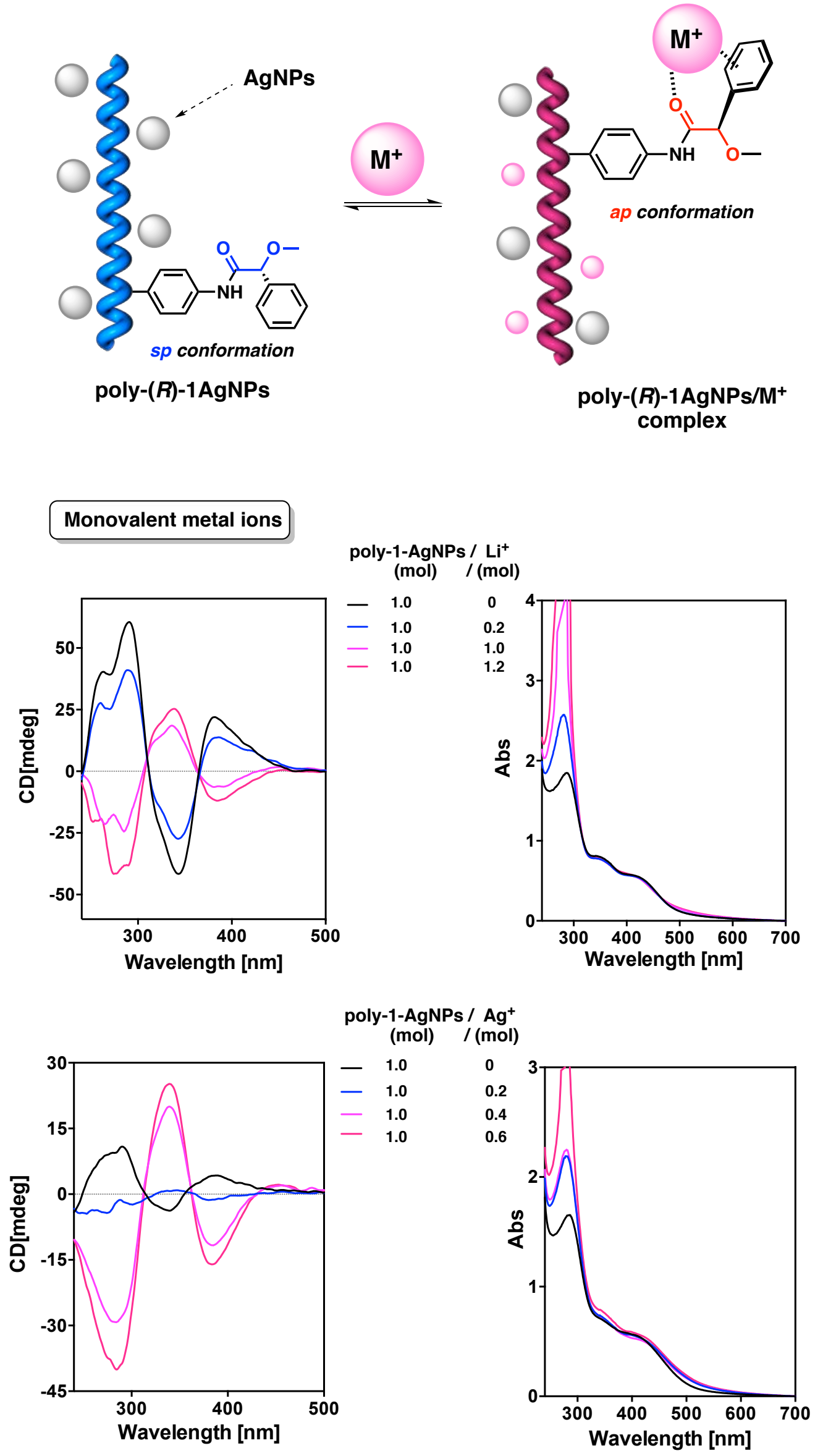

Figure S19. CD and UV-Vis studies of poly- $(R)-1-A g N P s$ in presence of monovalent metal ions. 
The addition of divalent metal ions $\left(10.0 \mathrm{mg} \mathrm{mL}^{-1}\right.$ in $\left.\mathrm{MeOH}\right)$ to poly-1-AgNPs $(0.3 \mathrm{mg}$ $\mathrm{mL}^{-1}$ in $\left.\mathrm{CHCl}_{3}\right)$ promotes a $s p$ conformation [dihedral angle for $(\mathrm{C}=\mathrm{O}-\mathrm{C}-\mathrm{OMe}) 0^{\circ} \mathrm{ca}$ ] in the pendant group leading to a right-handed helical sense due to the coordination of the divalent ions to carbonyl and methoxy groups.
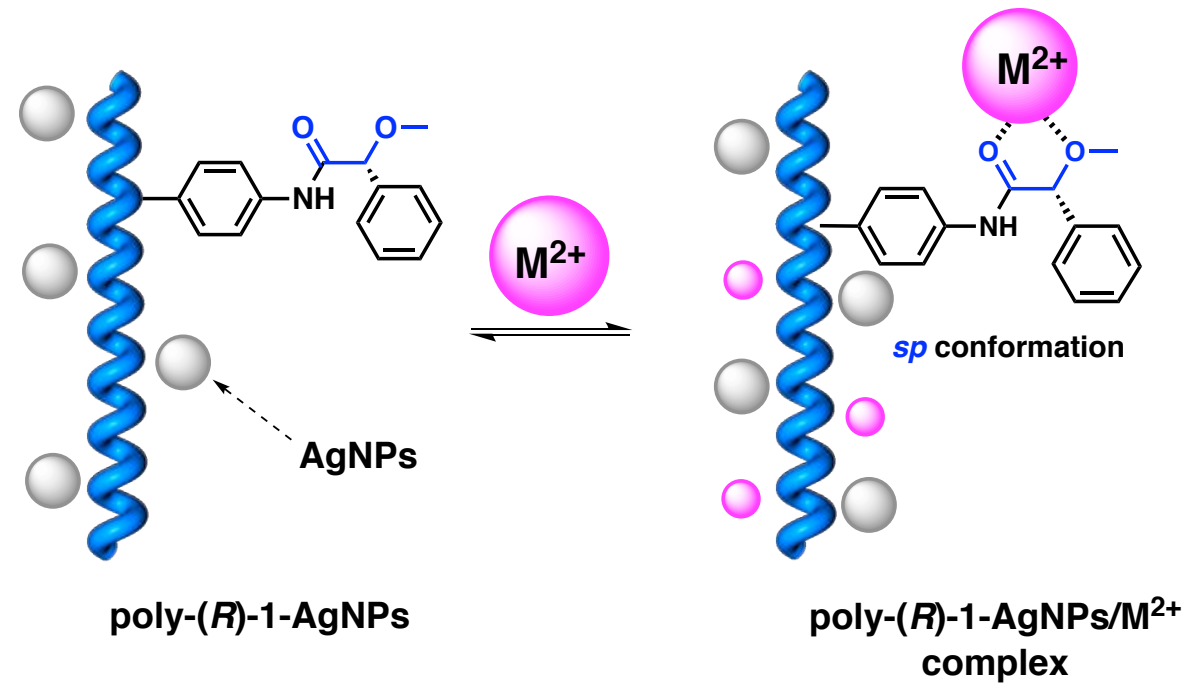

\section{Divalent metal ions}

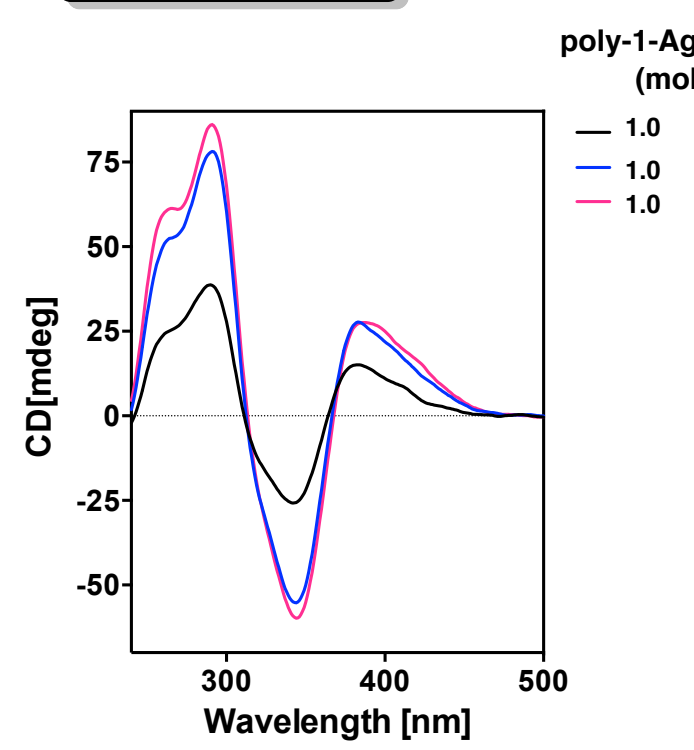

(mol) $/(\mathrm{mol})$

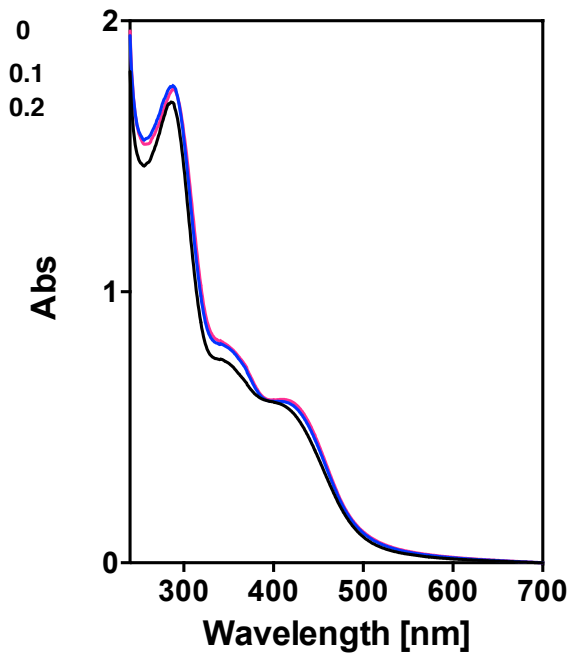

Figure S20. CD and UV-Vis studies of poly-1-AgNPs in presence of divalent metal ions.

\section{Microscopy studies of poly-1-AgNPs: SEM and TEM images}

SEM measurements were performed on a LEO-435VP electron microscope equipped with an energy dispersive X-ray (EDX) spectrometer.

TEM measurements were performed on a JEOL JEM 2010 and $200 \mathrm{KV}$ as a voltage.

A solution of poly- $(R)-1-\operatorname{AgNPs}\left(0.3 \mathrm{mg} \mathrm{mL}^{-1}\right)$ was drop casted onto of silicon wafer chip 
and allowed to dry at $\mathrm{rt}$ for $12 \mathrm{~h}$ and SEM images was carried out.

For TEM studies, a drop solution of poly- $(R)-1-\operatorname{AgNPs}\left(0.3 \mathrm{mg} \mathrm{mL}^{-1}\right)$ was settled onto carbon chip and allowed to dry at $\mathrm{rt}$ for $12 \mathrm{~h}$.

During these studies, the presence of AgNPs (size: $2.8 \pm 0.5 \mathrm{~nm}$ ) with a lineal distribution was observed.
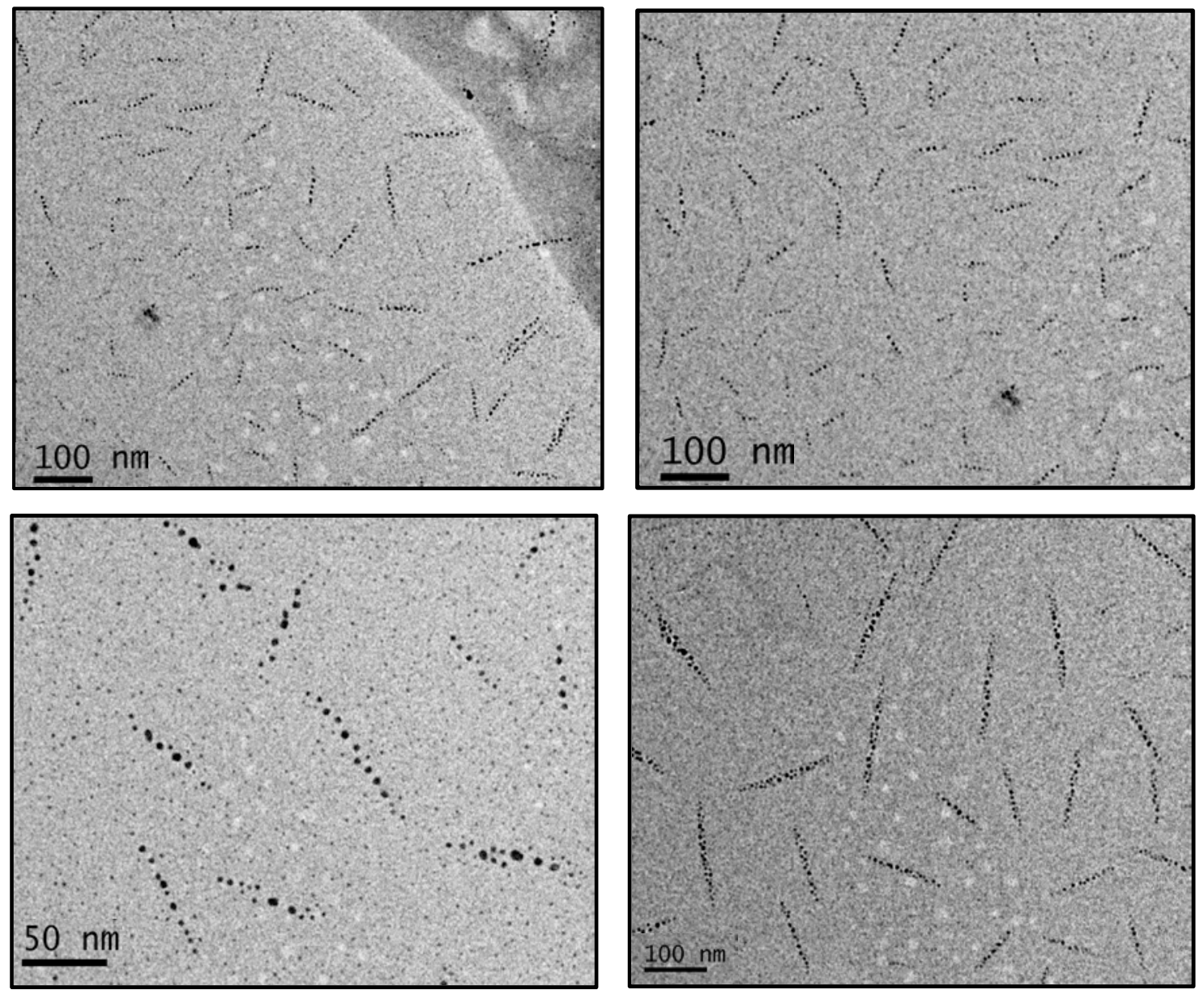

Figure S21. TEM images of poly-( $R$ )-1-AgNPs with lineal distribution (size: $2.8 \pm 0.5 \mathrm{~nm}$ ) 

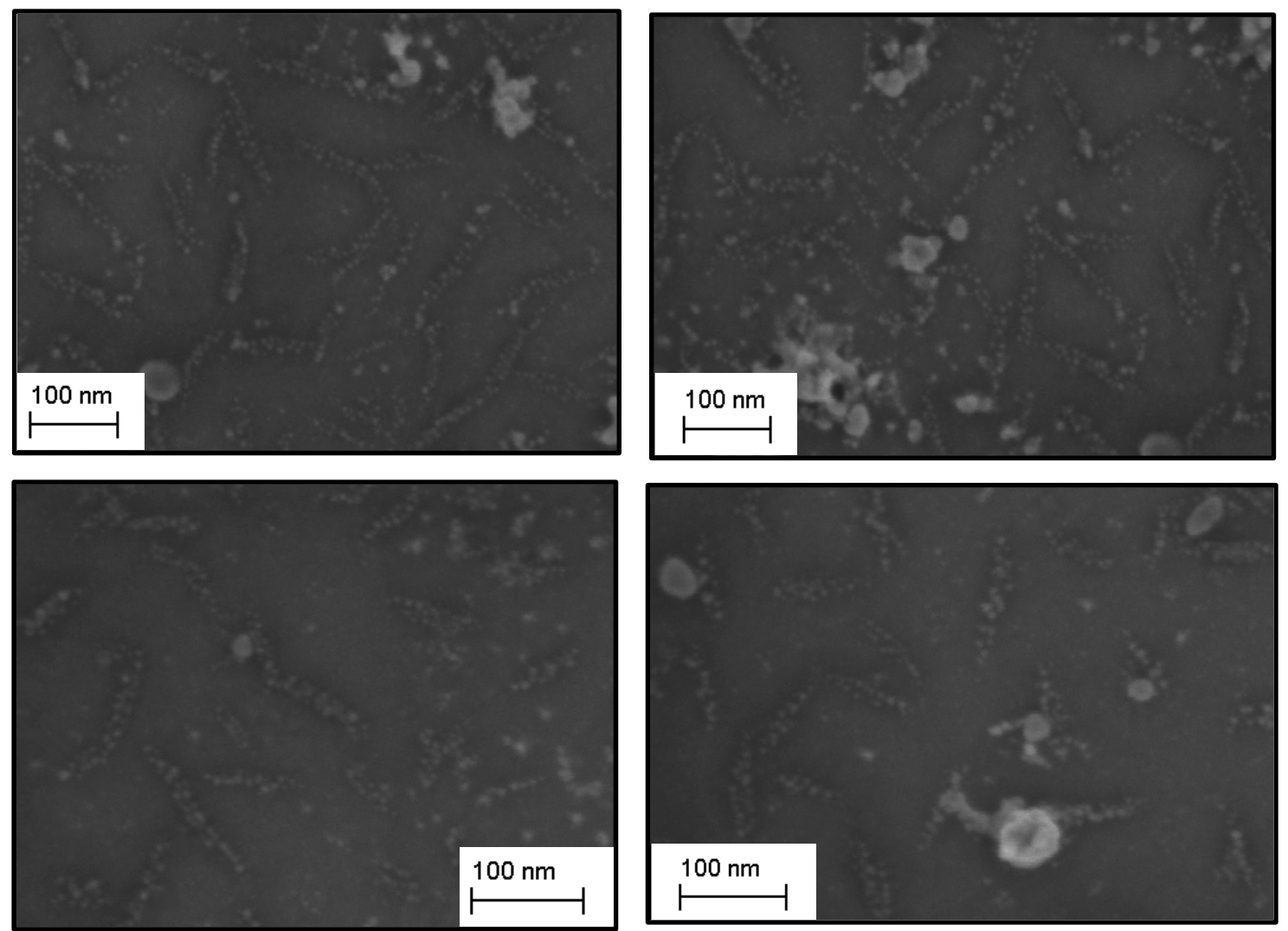

Figure S22. SEM images of poly-1-AgNPs with lineal distribution.

\section{Stability of poly-(R)-1-AgNPs/Na+ ${ }^{+}$with time}

The stability of poly- $(R)-\mathbf{1}-\mathrm{AgNPs} / \mathrm{Na}^{+}$nanocomposites were studied by UV-Vis experiments at different times. Poly- $(R)-1-\mathrm{AgNPs} / \mathrm{Na}^{+}\left(0.3 \mathrm{mg} \mathrm{mL}{ }^{-1}, \mathrm{CHCl}_{3}\right)$ showed a decrease in the LSPR band intensity indicating that the AgNPs aggregated with time.

The stability of the AgNPs in the nanocomposite was improved by adding 1dodecanethiol (0.2 equiv) to poly-(R)-1 after formation of AgNPs. UV-Vis spectra recorded at different times showed the same LSPR band intensity. 

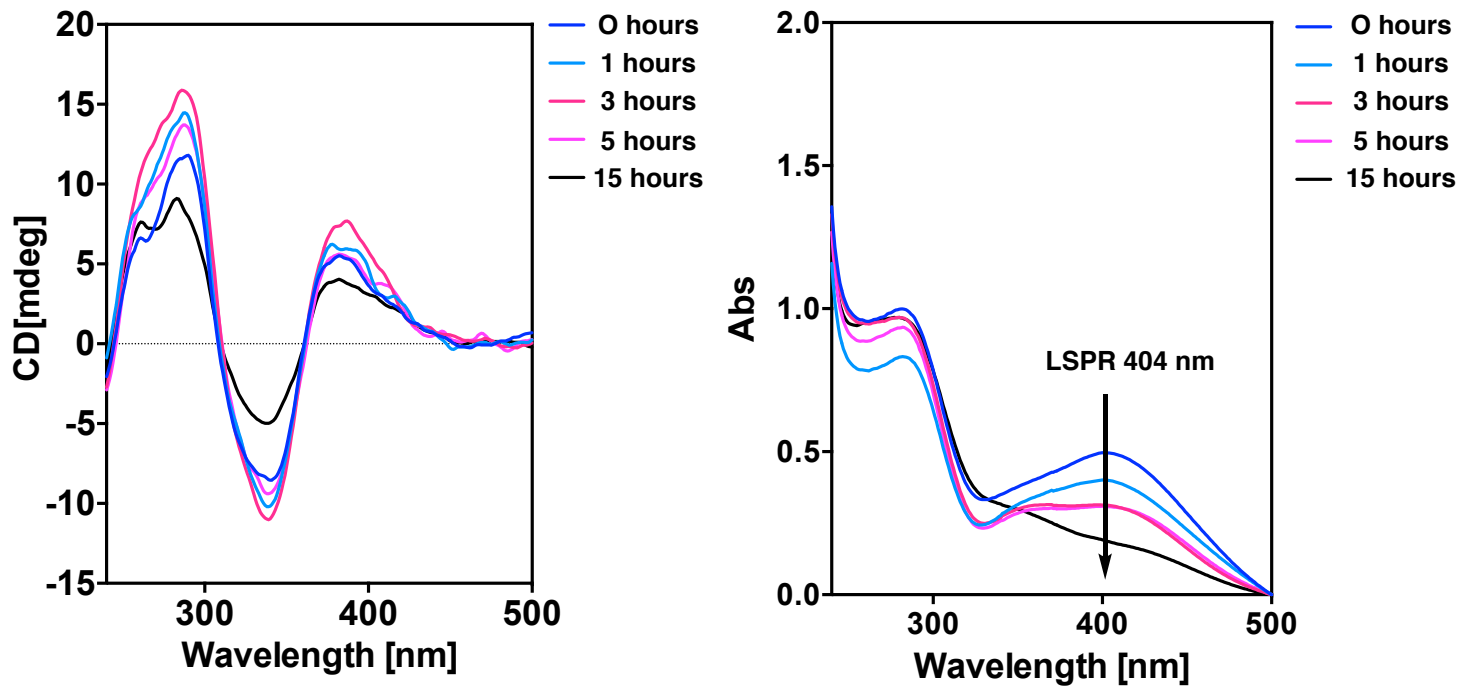

Figure S23. $\mathrm{CD}$ and UV-Vis for poly- $(R)-1-\mathrm{AgNPs} / \mathrm{Na}^{+}\left(0.3 \mathrm{mg} \mathrm{mL}^{-1}, \mathrm{CHCl}_{3}\right)$ at different times.

poly-(R)-1-AgNPs/Na+/dodecanethiol
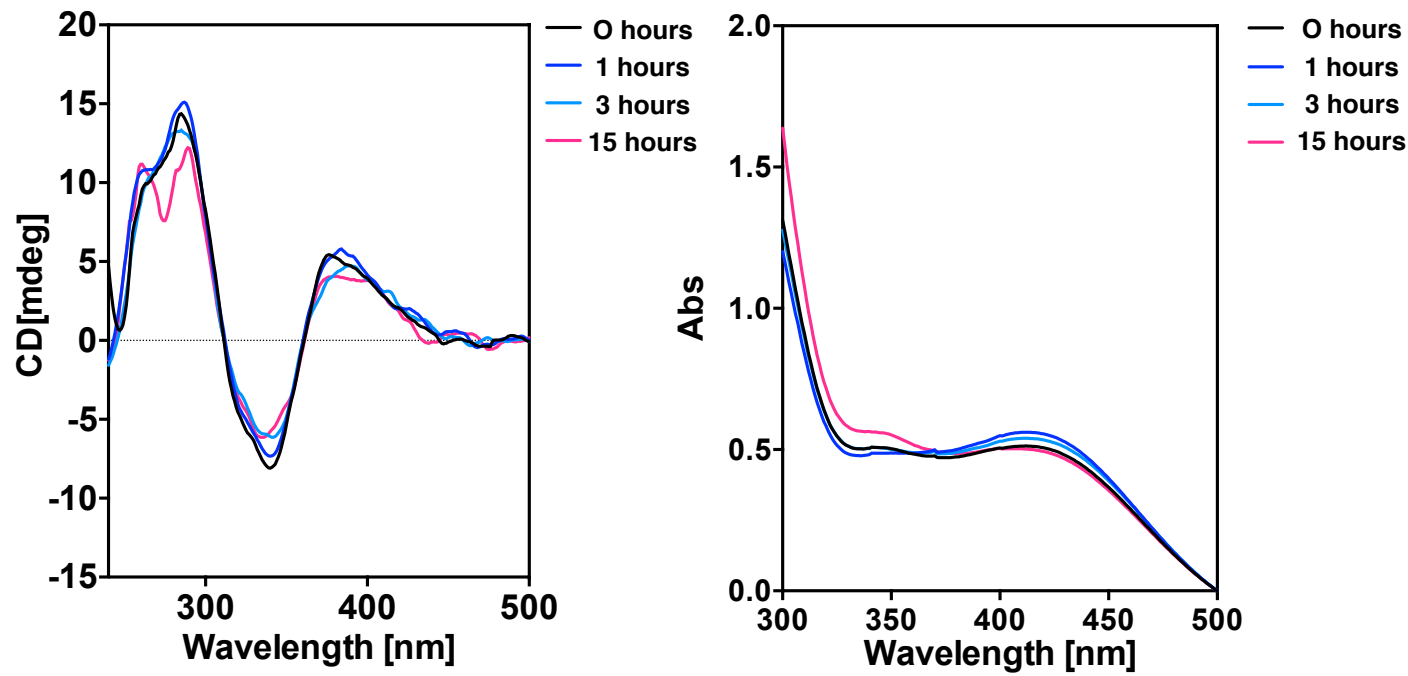

Figure S24. CD and UV-Vis for poly- $(R)-1-\mathrm{AgNPs} / \mathrm{Na}^{+}\left(0.3 \mathrm{mg} \mathrm{mL}^{-1}, \mathrm{CHCl}_{3}\right)$ at different times after addition of 1-dodecanethiol.

\section{TEM images of poly-(R)-1-AgNPs/Na $/$ dodecanethiol}

TEM measurements were performed on a JEOL JEM 2010 and $200 \mathrm{KV}$ as a voltage. A drop solution of poly- $(R)-1-\mathrm{AgNPs} / \mathrm{Na}^{+} /$dodecanethiol $\left(0.3 \mathrm{mg} \mathrm{mL} \mathrm{L}^{-1}\right)$ was settled onto carbon chip and allowed to dry at rt for $12 \mathrm{~h}$. 

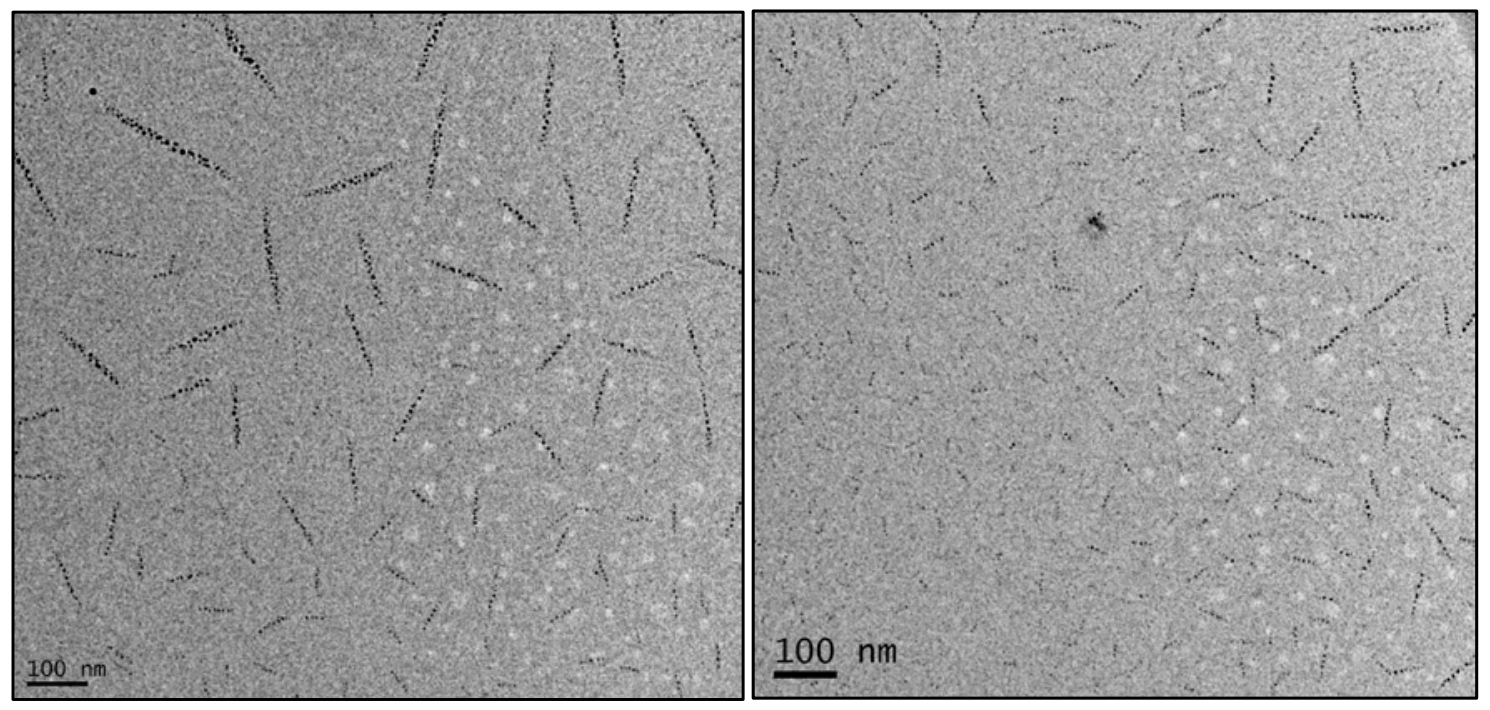

Figure S25. TEM images of poly-( $R)-1-\mathrm{AgNPs} / \mathrm{Na}^{+} /$dodecanethiol with lineal distribution

\section{Microscopy studies of poly-2-AgNPs: TEM images}

TEM measurements were performed on a JEOL JEM 2010 and $200 \mathrm{KV}$ as a voltage. A drop solution of poly-2-AgNPs $\left(0.3 \mathrm{mg} \mathrm{mL}^{-1}\right)$ was settled onto carbon chip and allowed to dry at $\mathrm{rt}$ for $12 \mathrm{~h}$. 

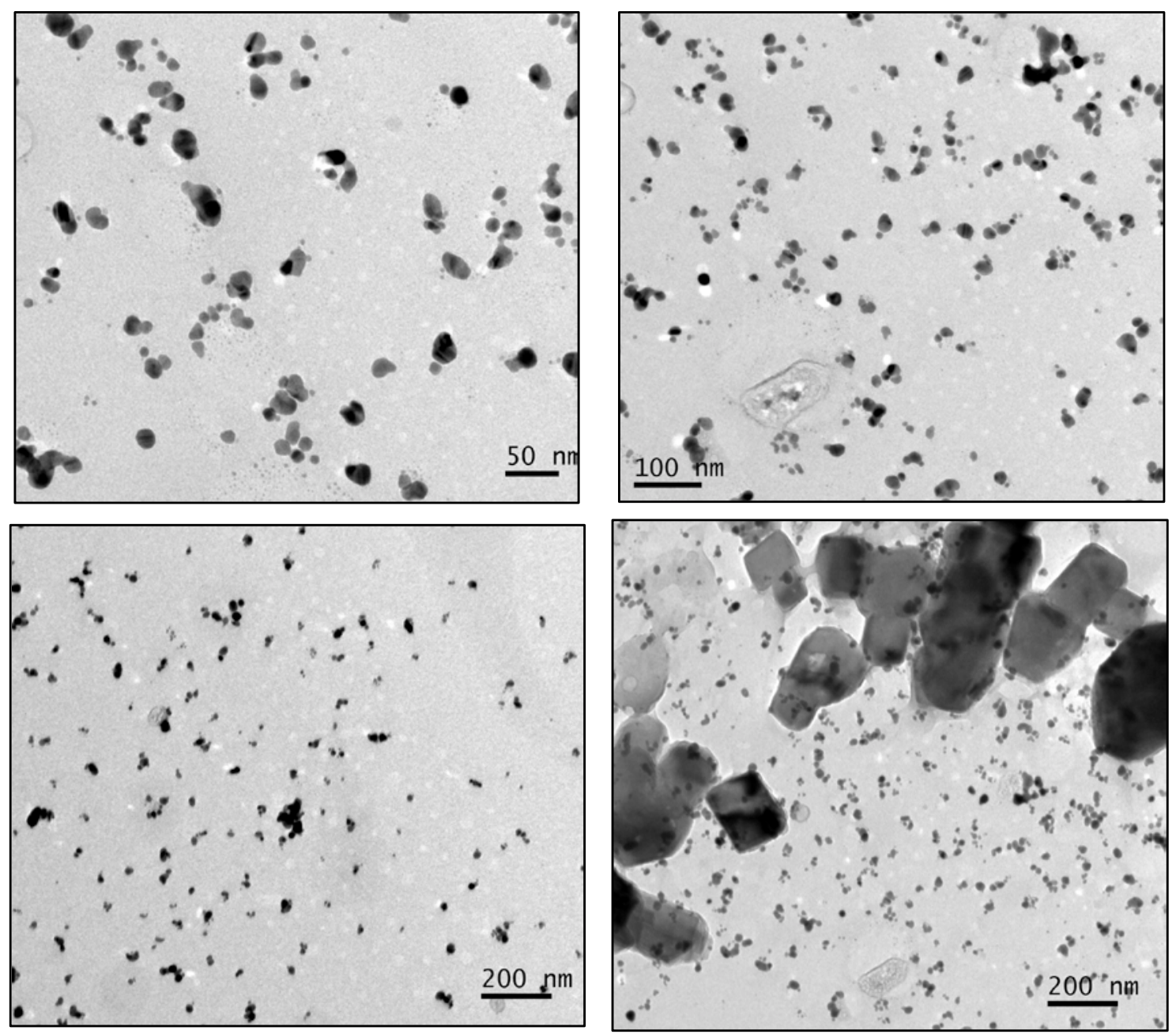

Figure S26. TEM images of poly-(R)-2-AgNPs

\section{Formation of poly-(R)-1-AgNPs using $\mathrm{LiBH}_{4}$}

Following the general procedure, poly- $(R)-1-\mathrm{AgNPs} / \mathrm{Li}^{+}$nanocomposites were prepared using $\mathrm{LiBH}_{4}$ as a reducing agent. First, all the glassware was washed with aqua regia, Milli Q water and acetone. The reaction was carried out at $\mathrm{rt}$ under an Ar atmosphere.

Polymer poly-(R)-1 was dissolved in $\mathrm{CHCl}_{3}\left(0.3 \mathrm{mg} \mathrm{mL}{ }^{-1}\right)$ and then, $\mathrm{AgClO}_{4}$ (0.5 equiv) in $\mathrm{MeOH}$ was added to form the poly- $(R)-1 / \mathrm{Ag}^{+}$complexes where the pendant groups adopt an ap conformation due to silver ions complexed with the carbonyl groups. Finally, $\mathrm{LiBH}_{4}(1$ equiv) in $\mathrm{MeOH}$ was added to form AgNPs. In this case, the $\mathrm{CD}$ spectra showed a negative Cotton effect indicating the complexation of the $\mathrm{Li}^{+}$ions to the carbonyl groups and the presence of $\mathrm{Li}^{+}-\pi \square$ interactions. 

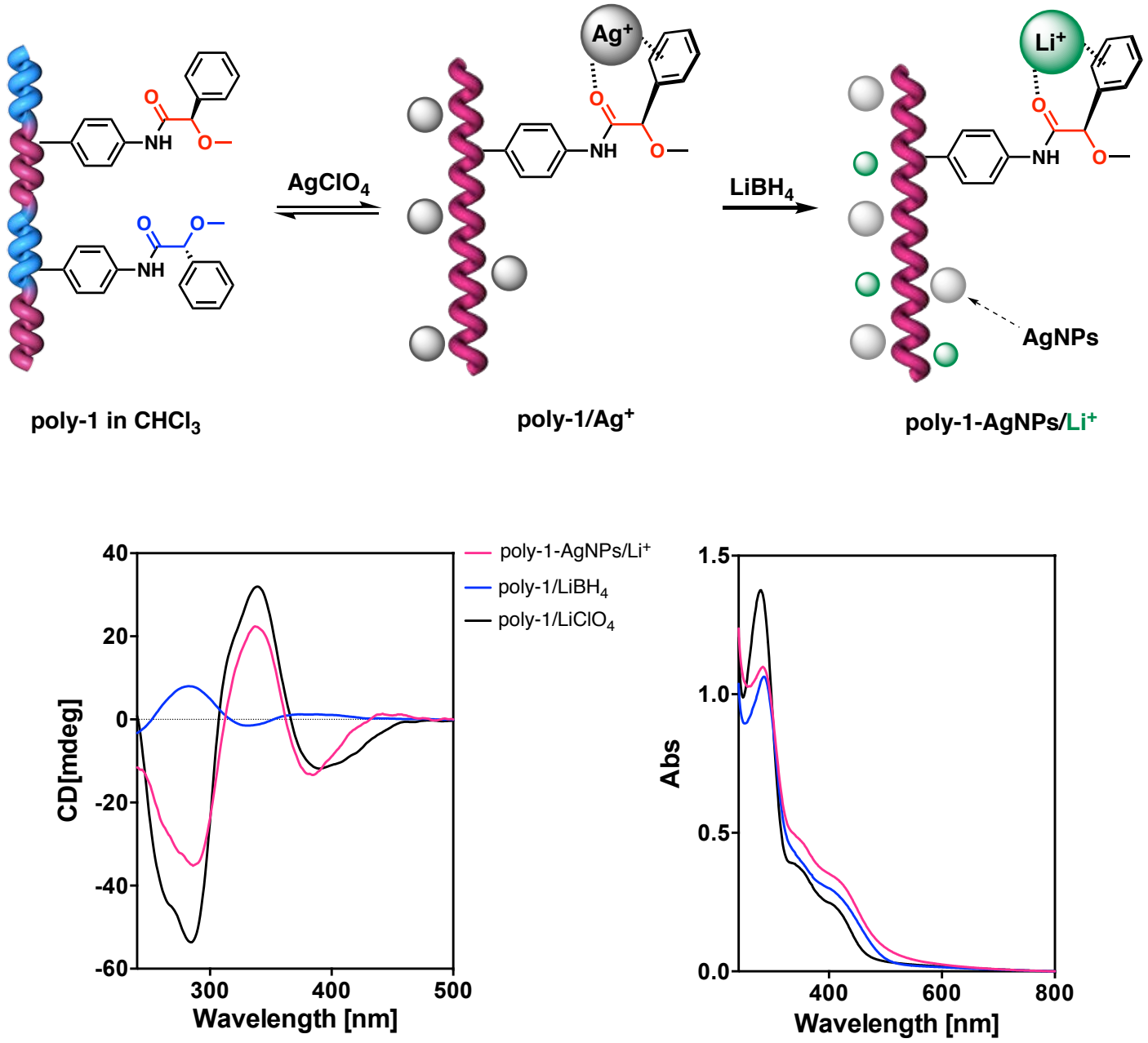

Figure S27. Role of $\mathrm{LiBH}_{4}$ in the helical sense of poly- $(R)-\mathbf{1}$.

\section{Effect of $\mathrm{NaBH}_{4}$ in the helical sense of poly-(R)-1-AgNPs/Na ${ }^{+}$}

The influence of $\mathrm{NaBH}_{4}$ in the helical sense of poly-(R)-1-AgNPs was studied by CD and $\mathrm{UV}-\mathrm{V}$ is experiments. Following the general procedure, poly- $(R)-1-\mathrm{AgNPs} / \mathrm{Na}^{+}$were prepared using $\mathrm{NaBH}_{4}$ as a reducing agent. $\mathrm{CD}$ experiments shows a positive Cotton effect indicating a $s p$ conformation between carbonyl and methoxy group in the pendant group.

$\mathrm{NaBH}_{4}$ (1 equiv, $10 \mathrm{mg} \mathrm{mL}{ }^{-1}$ ) was added to poly- $(R)-1$ as control experiment. CD experiments showed a null Cotton effect in the vinylic region $(380 \mathrm{~nm})$ indicating the absence of interaction between poly- $(R)-\mathbf{1}$ and $\mathrm{NaBH}_{4}$. 

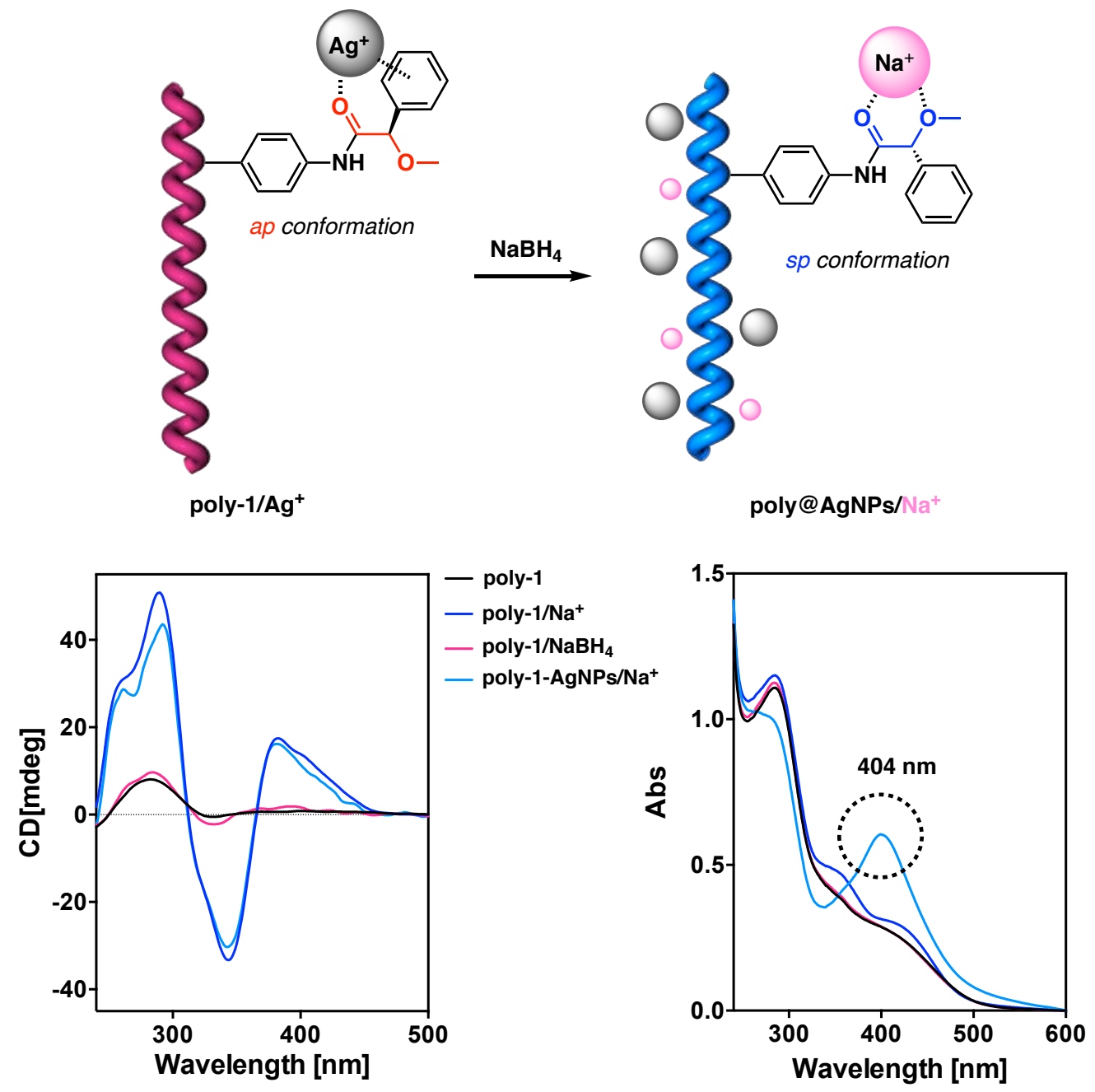

Figure S28. Influence of the $\mathrm{NaBH}_{4}$ in the helical sense of poly- $(R)-\mathbf{1}-\mathrm{AgNPs}$.

\section{Role of $\mathrm{Na}^{+}$cations in the helicity of poly-(R)-1-AgNPs/Na+}

$\mathrm{CD}$ experiments showed a negative Cotton Effect when $\mathrm{Ag}^{+}\left(0.5\right.$ equiv, $\left.10 \mathrm{mg} \mathrm{mL}^{-1}\right)$ in $\mathrm{MeOH}$ was added to a solution of poly- $(R)-\mathbf{1}\left(0.3 \mathrm{mg} \mathrm{mL}^{-1}\right)$ in $\mathrm{CHCl}_{3}$. These experiments confirmed the presence of left-handed helices due to the chelation of $\mathrm{Ag}^{+}$ions to the carbonyl groups and the presence of $\mathrm{Ag}^{+}-\pi \square$ interaction.[S3]

On the other hand, CD experiments showed a positive Cotton Effect when $\mathrm{NaBH}_{4}(1$ equiv, $\left.1 \mathrm{mg} \mathrm{mL}{ }^{-1}\right)$ was added to a solution of poly- $(R)-1 / \mathrm{Ag}^{+}$complex $(0.3 \mathrm{mg} / \mathrm{mL})$ to form poly- $(R)-1-\mathrm{AgNPs} / \mathrm{Na}^{+}$. 

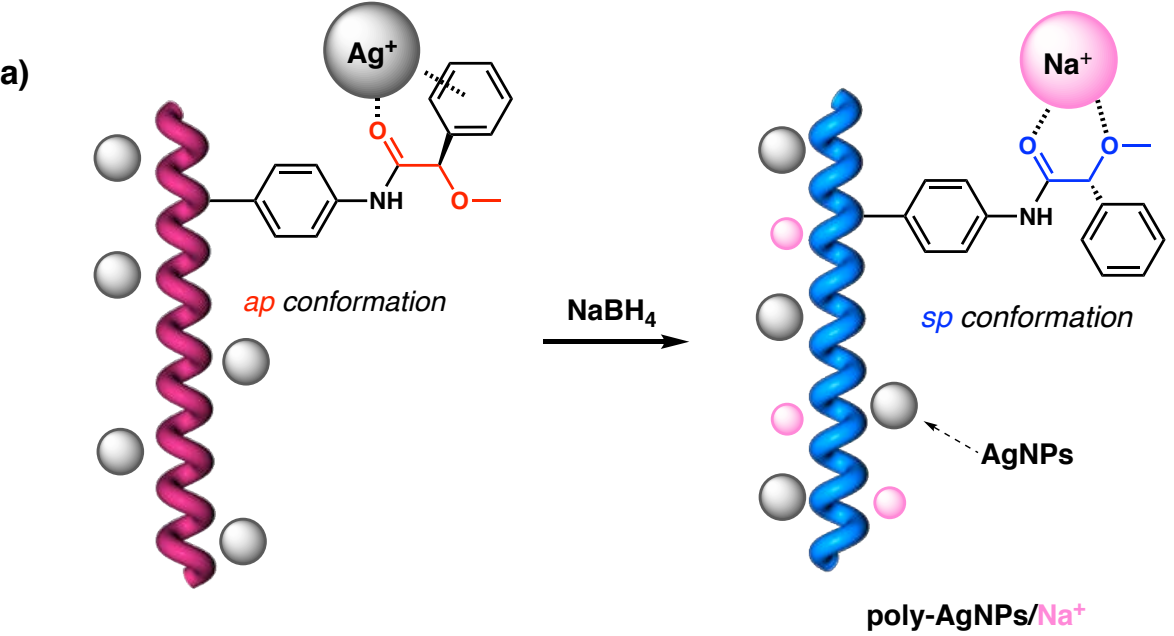

b)
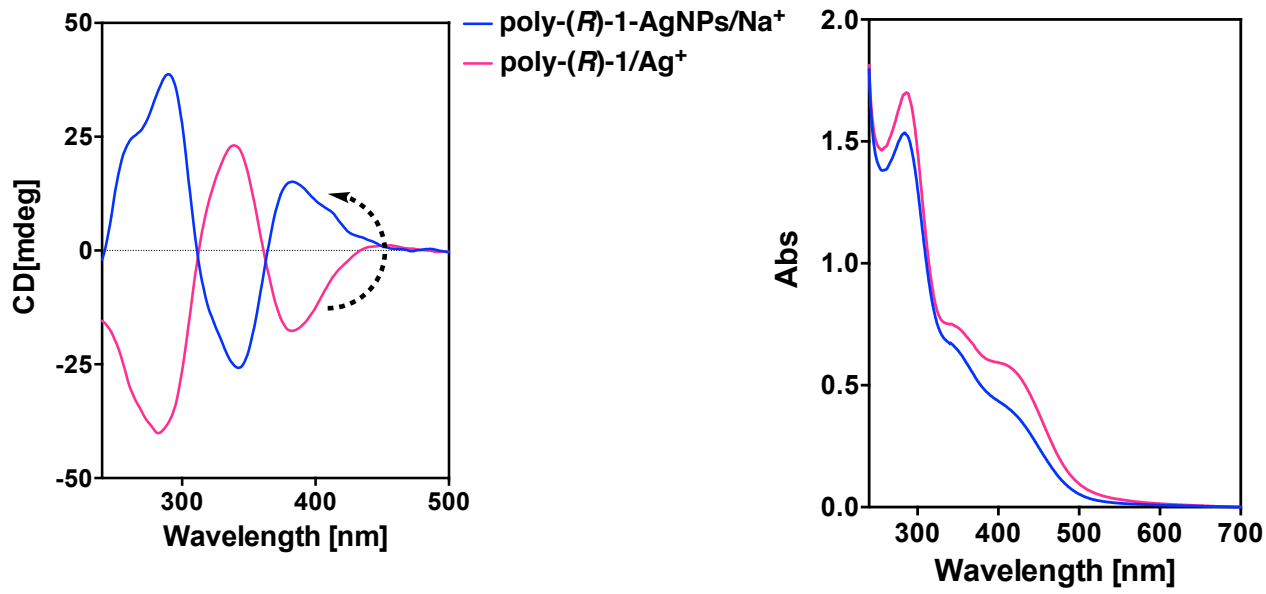

c)
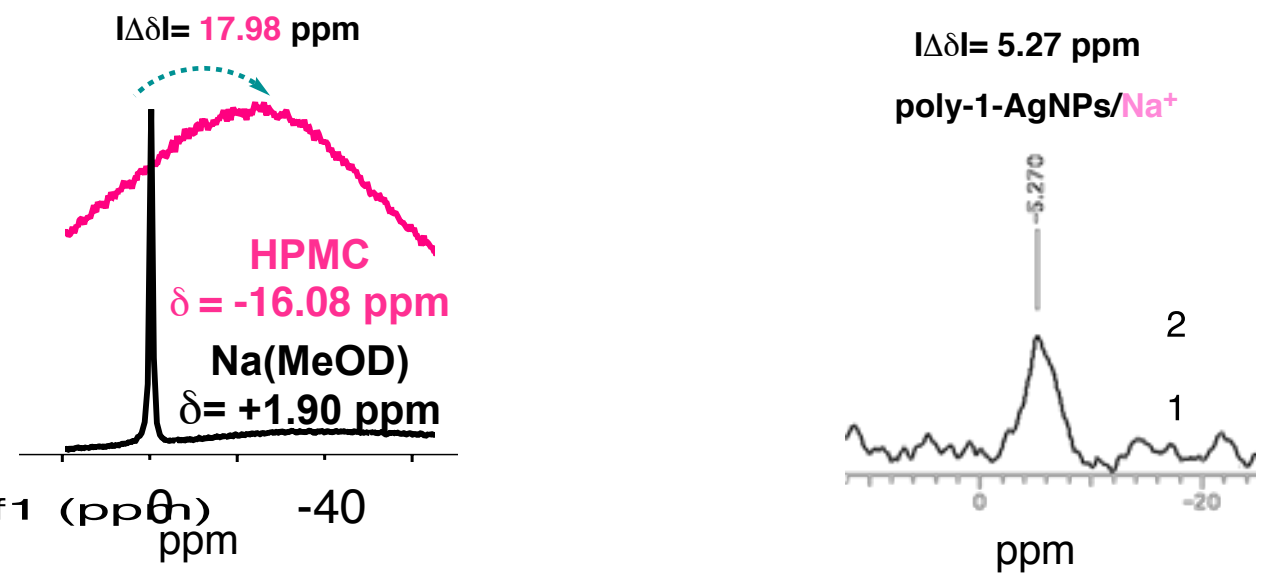

Figure S29. a) Schematic representation of the role of $\mathrm{NaBH}_{4}$ in the helical sense of poly- $(R)-1$ $\mathrm{AgNPs} / \mathrm{Na}^{+}$. b) CD and UV-Vis spectra of poly- $(R)-\mathbf{1} / \mathrm{Ag}^{+}$and poly- $(R)-\mathbf{1}-\mathrm{AgNPs} / \mathrm{Na}^{+}$. c) ${ }^{23} \mathrm{Na} \mathrm{NMR}$ of poly- $(R)-1-\mathrm{AgNPs} / \mathrm{Na}^{+}$showing the absence of $\mathrm{Na}^{+}-\pi \square$ interaction. 


\section{Experiments with metal scavenger resins}

Commercially available Quadrapure ${ }^{\mathrm{TM}}$ (Aldrich) resins (MPA, TU, IDA) were employed as metal scavenger resins. These resins contain different functional groups that interact with metal ions. The TU resin contains a thiourea functional group, IDA possess an imino diacetate group and the MPA resin a mercaptophenyl amino group.<smiles>NC(=S)NC=O</smiles>

\section{Quadrapure TU}<smiles>O=CN(CC(=O)O)CC(=O)O</smiles>

Quadrapure IDA<smiles>O=CNc1ccccc1S</smiles>

\section{Quadrapure MPA}

Figure S30. Chemical structure of metal scavenger resins (Quadrapure TU, IDA, MPA).

To carry out these experiments, the resins were swollen in $\mathrm{CHCl}_{3}$ for $1 \mathrm{~h}\left(0.05 \mathrm{~g} \mathrm{~mL}^{-1}\right)$. Next, $100 \mathrm{mg}$ of resin were added to a solution of poly- $(R)-1-\operatorname{AgNPs} / \mathrm{Na}^{+}\left(0.3 \mathrm{mg} \mathrm{mL}{ }^{-1}\right.$ in $\mathrm{CHCl}_{3}$ ). After $30 \mathrm{~min}$, the $\mathrm{CD}$ and $\mathrm{UV}-\mathrm{Vis}$ spectra confirmed that $\mathrm{Na}^{+}$ions promoted the helical sense in poly- $(R)-1-\mathrm{AgNPs} / \mathrm{Na}^{+}$.
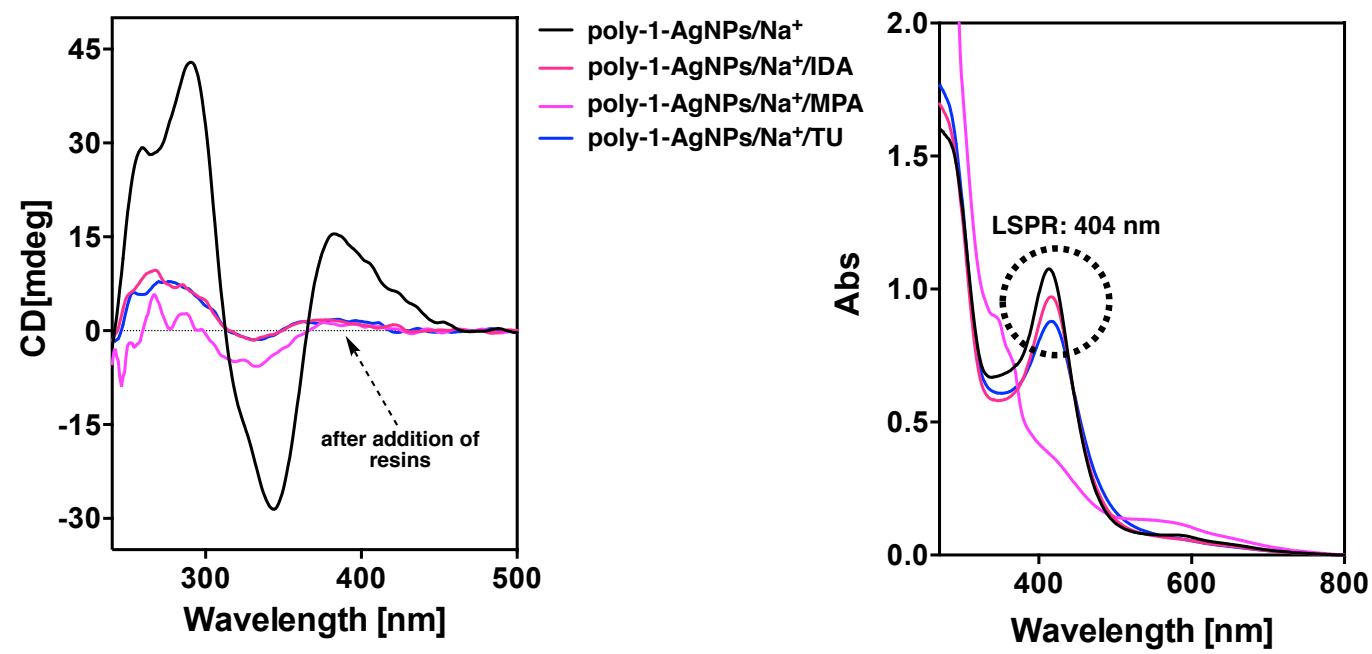

Figure S31. CD and UV-Vis spectra of poly- $(R)-1-\mathrm{AgNPs} / \mathrm{Na}^{+}$in presence of resins metal scavengers (MPA, TU and IDA). 


\section{Formation of chiral nanospheres using poly- $(R)-1-$}

\section{AgNPs/dodecanethiol and monovalent and divalent metal ions}

The addition of $\mathrm{Ag}^{+}\left(10 \mathrm{mg} \mathrm{mL} \mathrm{mL}^{-1}\right)$ in $\mathrm{MeOH}$ to a solution of poly- $(R)-\mathbf{1 -}$ AgNPs/dodecanethiol $\left(0.3 \mathrm{mg} \mathrm{mL}{ }^{-1}\right)$ in $\mathrm{CHCl}_{3}$ produces left-handed helices indicating the chelation of $\mathrm{Ag}^{+}$ions to the carbonyl group and the presence of $\mathrm{Ag}^{+}-\pi \square$ interactions.

SEM measurements showed the formation of low polydisperse polymeric nanospheres due to the ability of the metal ions to act as crosslinking agents between polymer chains.

a)

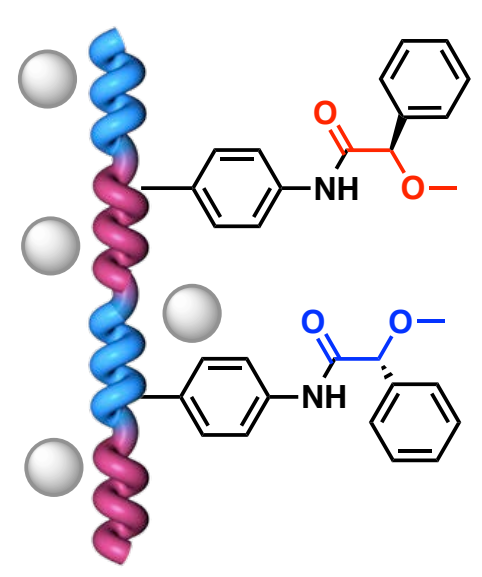

poly-(R)-1-AgNPs
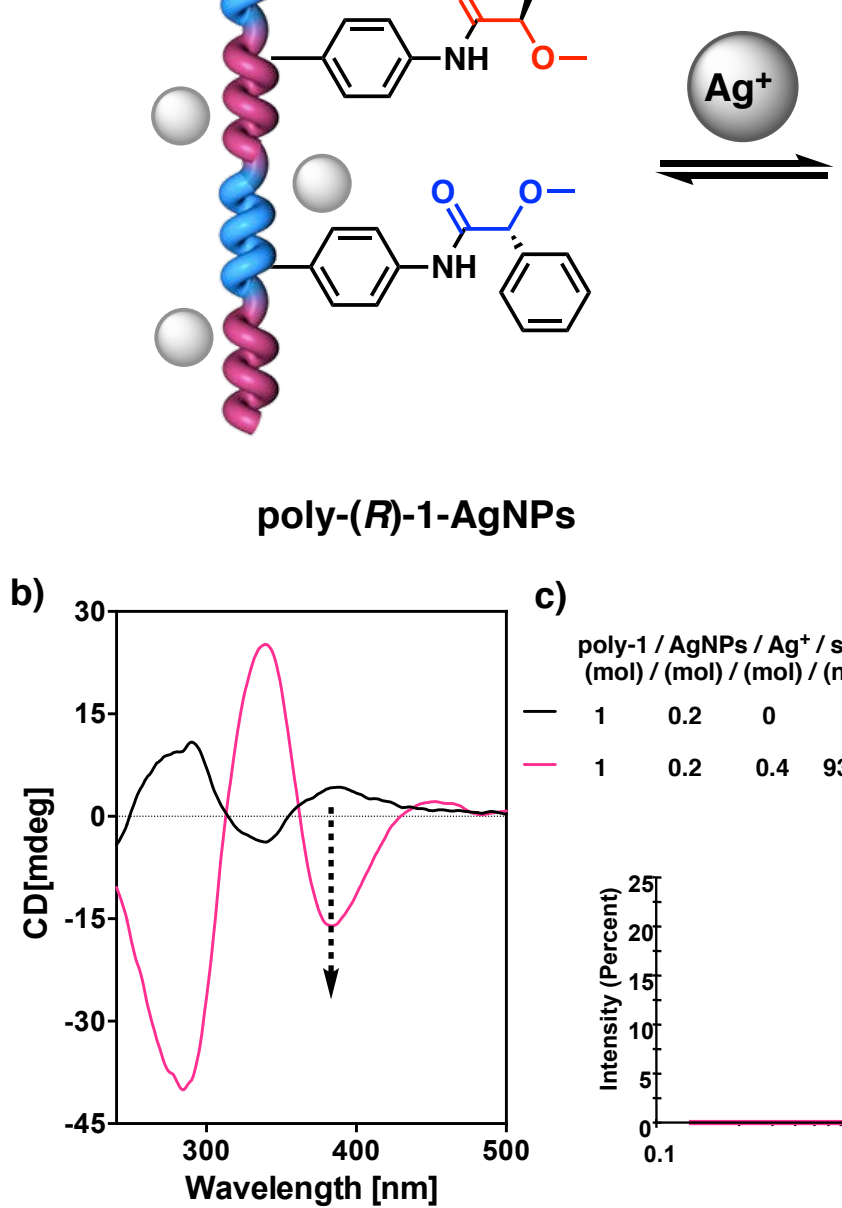

c)

poly-1 / AgNPs / $\mathrm{Ag}^{+} /$size / pdi

(mol) / (mol) / (mol) / (nm)

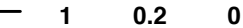

$\begin{array}{rrrrr}1 & 0.2 & 0.4 & 93 & 0.821\end{array}$

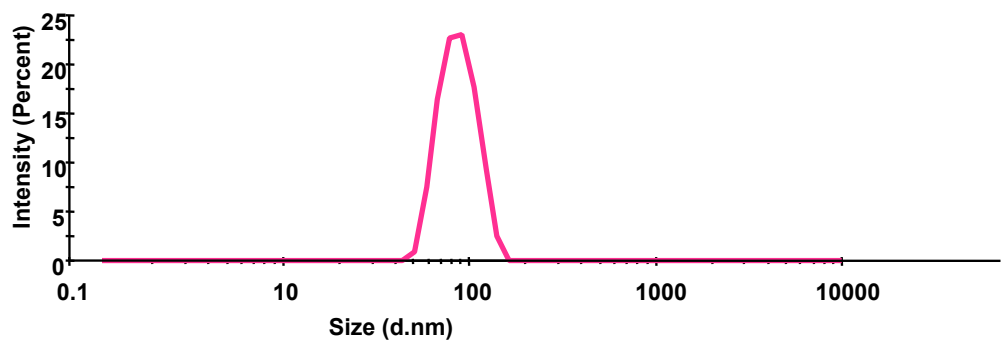



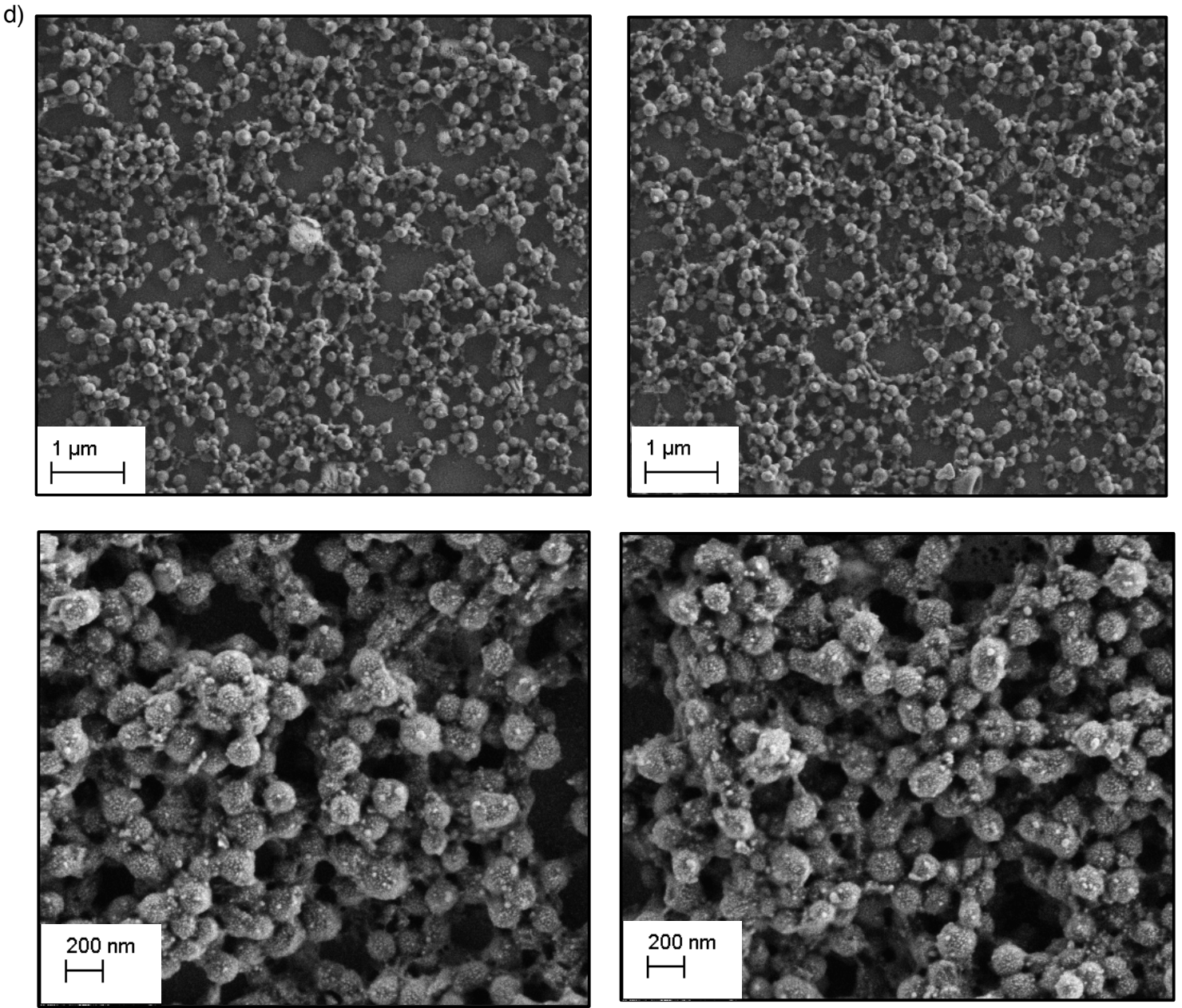

Figure S32. a) Schematic representation for the poly- $(R)-1-\mathrm{AgNPs} /$ dodecanethiol/ $\mathrm{Ag}^{+}$. b) $\mathrm{CD}$ traces for poly- $(R)-1-A g N P s / d o d e c a n e t h i o l$ and poly- $(R)-1-A g N P s / d o d e c a n e t h i o l / \mathrm{Ag}^{+}$. c) DLS studies for poly- $(R)-$ 1-AgNPs/dodecanethiol and poly-(R)-1-AgNPs/dodecanethiol/ $\mathrm{Ag}^{+}$. d) SEM images for poly- $(R)-1-$ AgNPs/dodecanethiol $/ \mathrm{Ag}^{+}$nanospheres.

The addition of $\mathrm{Ba}^{2+}$ ions $\left(10 \mathrm{mg} \mathrm{mL}{ }^{-1}\right)$ in $\mathrm{MeOH}$ to a solution of poly- $(R)-\mathbf{1 -}$ AgNPs/dodecanethiol $\left(0.3 \mathrm{mg} \mathrm{mL} L^{-1}\right)$ in $\mathrm{CHCl}_{3}$ produces right-handed helices indicating the chelation of $\mathrm{Ba}^{2+}$ to carbonyl and methoxy groups.

SEM measurements showed the formation of low polydisperse polymeric nanospheres due to the ability of the metal ions to act as crosslinking agents between polymer chains. 
a)

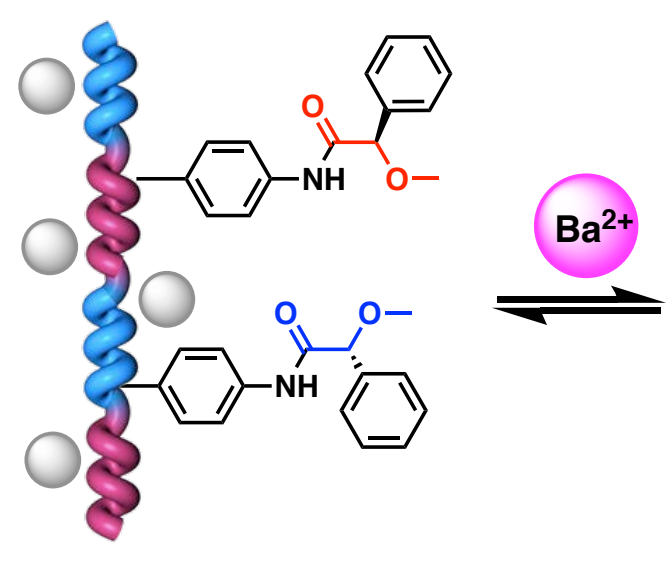

poly-(R)-1-AgNPs

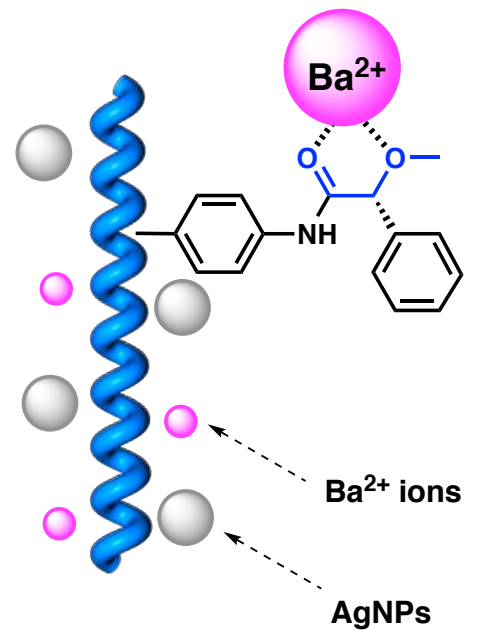

poly-(R)-1-AgNPs/Ba ${ }^{2+}$ b)

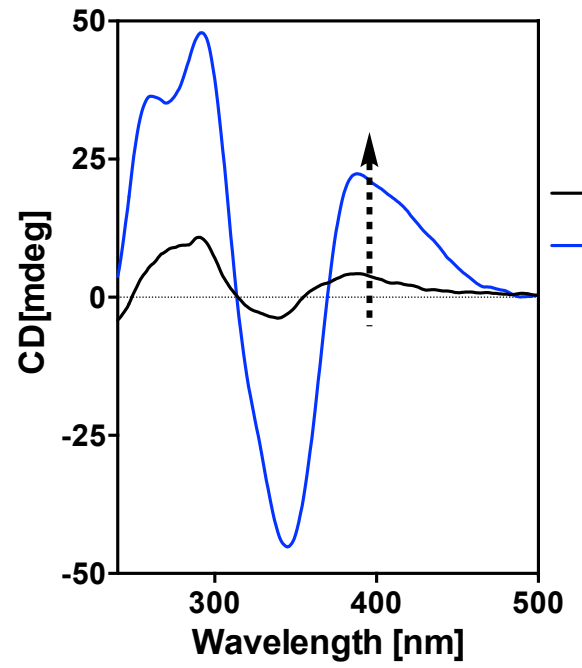

c)

poly-1/ AgNPs/ $\mathrm{Ba}^{2+} /$ size/ pdi $(\mathrm{mol}) /(\mathrm{mol}) /(\mathrm{mol}) /(\mathrm{nm})$

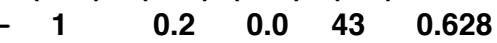

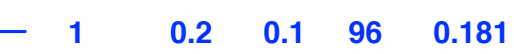

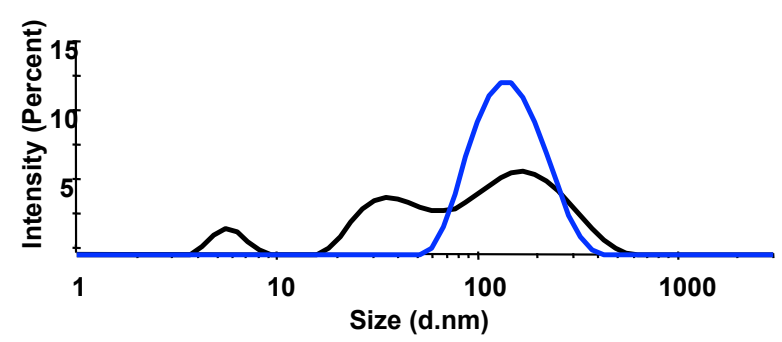


d)
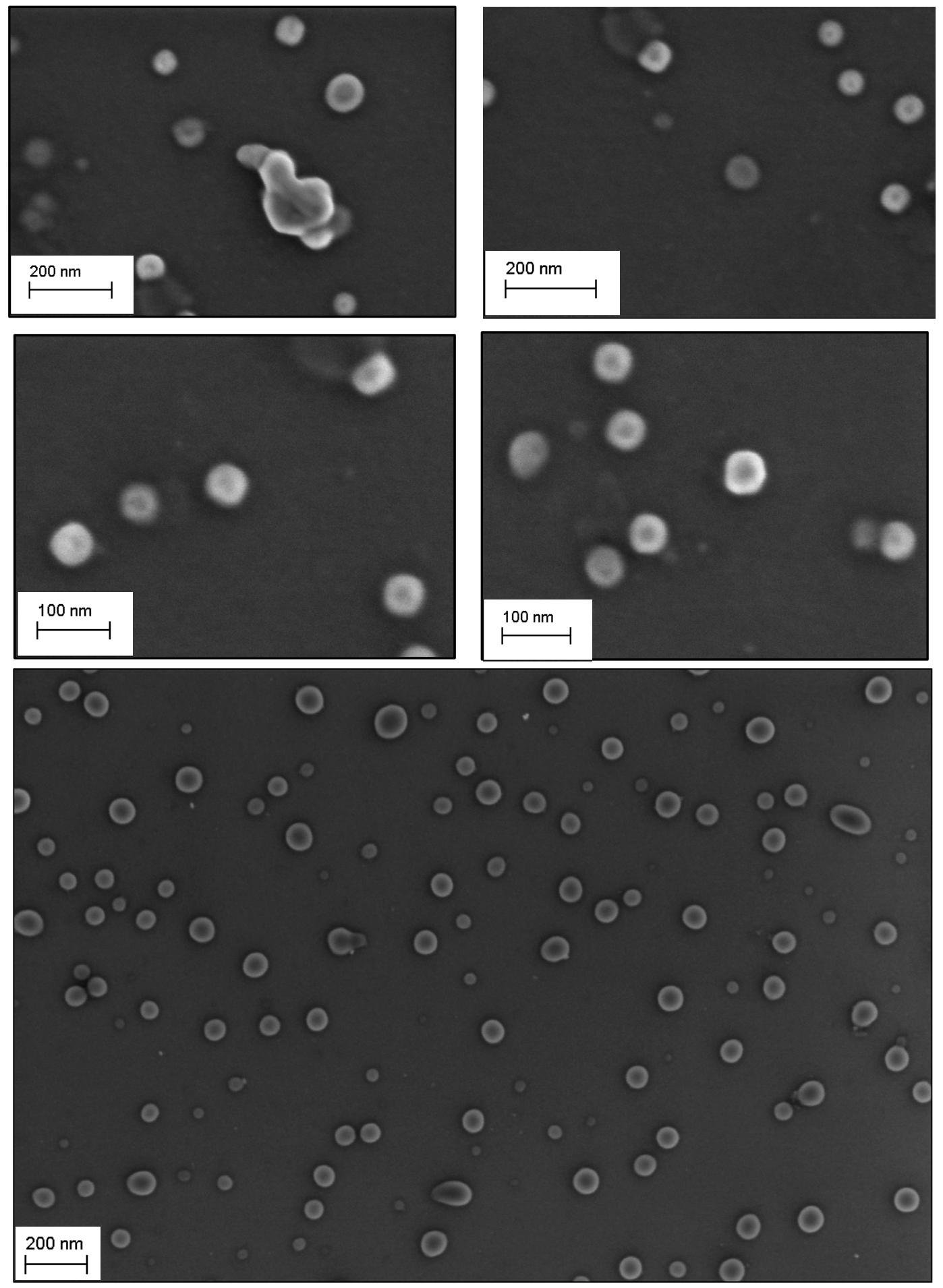

Figure S33. a) Schematic representation for the poly- $(R)-1-\mathrm{AgNPs} /$ dodecanethiol $/ \mathrm{Ba}^{2+}$. b) $\mathrm{CD}$ traces for poly- $(R)-1-\mathrm{AgNPs} /$ dodecanethiol and poly-( $R$ )-1-AgNPs/dodecanethiol $/ \mathrm{Ba}^{2+}$. c) DLS studies for poly$(R)$-1-AgNPs/dodecanethiol and poly- $(R)-\mathbf{1}-\mathrm{AgNPs} /$ dodecanethiol $/ \mathrm{Ba}^{2+}$. d) SEM images for poly- $(R)-\mathbf{1 -}$ AgNPs/dodecanethiol/ $\mathrm{Ba}^{2+}$ nanospheres (size: $61 \pm 21 \mathrm{~nm}, 120$ nanoparticles). 


\section{Control studies: "Enantiomer comparison"}

\subsection{CD studies of poly-(R)-1 and poly-(S)-1}
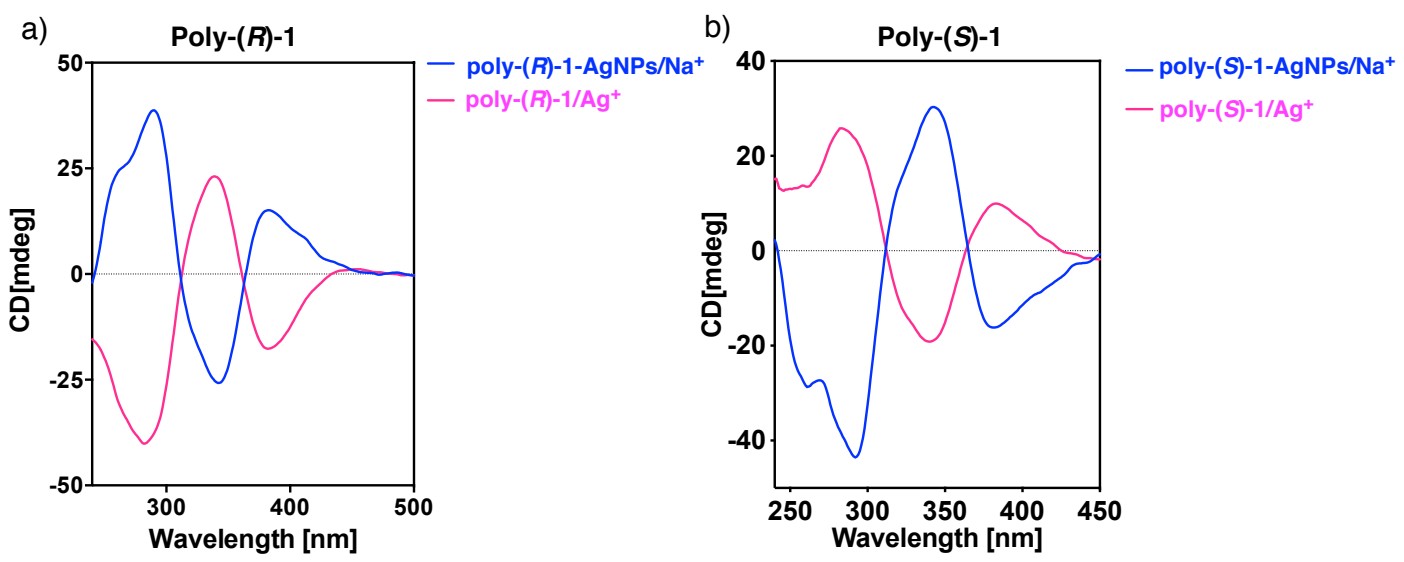

Figure S34. CD studies of a) poly- $(R)-\mathbf{1} / \mathrm{Ag}^{+}$, poly- $(R)-1-\mathrm{AgNPs} / \mathrm{Na}^{+}$and b) poly- $(S)-\mathbf{1} / \mathrm{Ag}^{+}$, poly- $(S)-\mathbf{1 -}$ $\mathrm{AgNPs} / \mathrm{Na}^{+}$.

\section{Control studies: "the thiol linkage" poly- $\left[(R)-1_{\mathrm{r}}-\operatorname{co}-\mathrm{B}_{1-\mathrm{r}}\right]$}

\subsection{Synthesis of poly- $\left[(R)-1_{r}-c o-3_{1-r}\right](r=0.01-0.05)$ series}

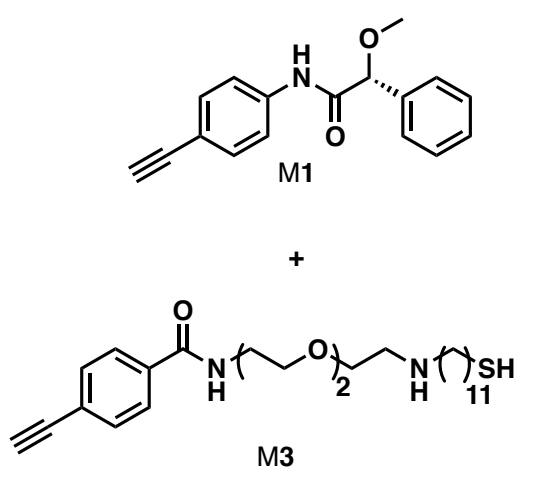

M3

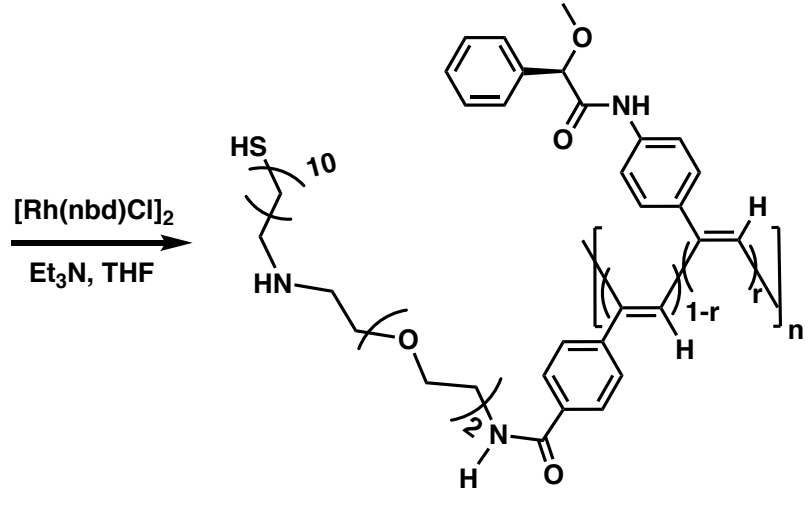

$$
\begin{gathered}
\text { poly-(1 } \left.\mathbf{1}_{\mathrm{r}}-c 0-\mathbf{3}_{1-\mathrm{r}}\right) \\
\mathrm{r}=95-99 \%
\end{gathered}
$$

The synthesis of monomer M3 can be found in the reference [S5].

Following the general procedure quantities of M1, M3, $\mathrm{Et}_{3} \mathrm{~N},[\mathrm{Rh}(\mathrm{nbd}) \mathrm{Cl}]_{2}$, and THF as shown in Table S4 were employed. Reaction yield is also indicated in the Table S4.

Table S4:

\begin{tabular}{|c|c|c|c|c|c|c|c|c|}
\hline Copolymer & $\begin{array}{c}\text { M1 } \\
\text { (mg) }\end{array}$ & $\begin{array}{c}\text { M1 } \\
\text { (mmol) }\end{array}$ & $\begin{array}{c}\text { M3 } \\
\text { (mg) }\end{array}$ & $\begin{array}{c}\text { M3 } \\
\text { (mmol) }\end{array}$ & $\begin{array}{l}\text { Cat } \\
\text { (mg) }\end{array}$ & $\begin{array}{l}\text { THF } \\
(\mathrm{mL})\end{array}$ & $\begin{array}{l}E \mathbf{t}_{3} \mathbf{N} \\
(\mu \mathrm{L})\end{array}$ & $\begin{array}{c}\text { Yield } \\
(\%)\end{array}$ \\
\hline poly- $\left[(R)-\mathbf{1}_{0.95}-C O-\mathbf{3}_{0.05}\right]$ & 94.9 & 0.358 & 5.1 & 0.018 & 0.576 & 0.75 & 7 & 82 \\
\hline poly- $\left[(R)-\mathbf{1}_{0.96}-c o-\mathbf{3}_{0.04}\right]$ & 95.6 & 0.362 & 4.1 & 0.015 & 0.576 & 0.75 & 7 & 90 \\
\hline poly- $\left[(R)-\mathbf{1}_{0.97}-\mathrm{Co}-\mathbf{3}_{0.03}\right]$ & 96.9 & 0.366 & 3.1 & 0.011 & 0.576 & 0.75 & 7 & 91 \\
\hline
\end{tabular}




$\begin{array}{lllllllll}\text { poly-[(R)-1 } \mathbf{1}_{\left.0.98-c o-\mathbf{3}_{0.02}\right]} & 97.7 & 0.369 & 2.1 & 0.008 & 0.576 & 0.75 & 7 & 75 \\ \text { poly-[(R)-1 } \mathbf{1}_{\left.0.99-c o-\mathbf{3}_{0.01}\right]} & 99.0 & 0.374 & 1.0 & 0.004 & 0.576 & 0.75 & 7 & 88\end{array}$

Table S5: GPC data

\section{$\mathbf{M}_{\mathrm{p}} \quad$ PDI}

\begin{tabular}{lll}
\hline poly- $\left[(R)-\mathbf{1}_{0.95}-c o-\mathbf{3}_{0.05}\right]$ & 15711 & 3.42 \\
poly- $\left[(R)-\mathbf{1}_{0.96}-c o-\mathbf{3}_{0.04}\right]$ & 18673 & 3.01 \\
poly- $\left[(R)-\mathbf{1}_{0.97-c o-\mathbf{3}_{0.03}}\right]$ & 27050 & 3.28 \\
poly- $\left[(R)-\mathbf{1}_{0.98}-c o-\mathbf{3}_{0.02}\right]$ & 28321 & 2.56 \\
poly- $\left[(R)-\mathbf{1}_{0.99}-c o-\mathbf{3}_{0.01}\right]$ & 30524 & 2.87
\end{tabular}

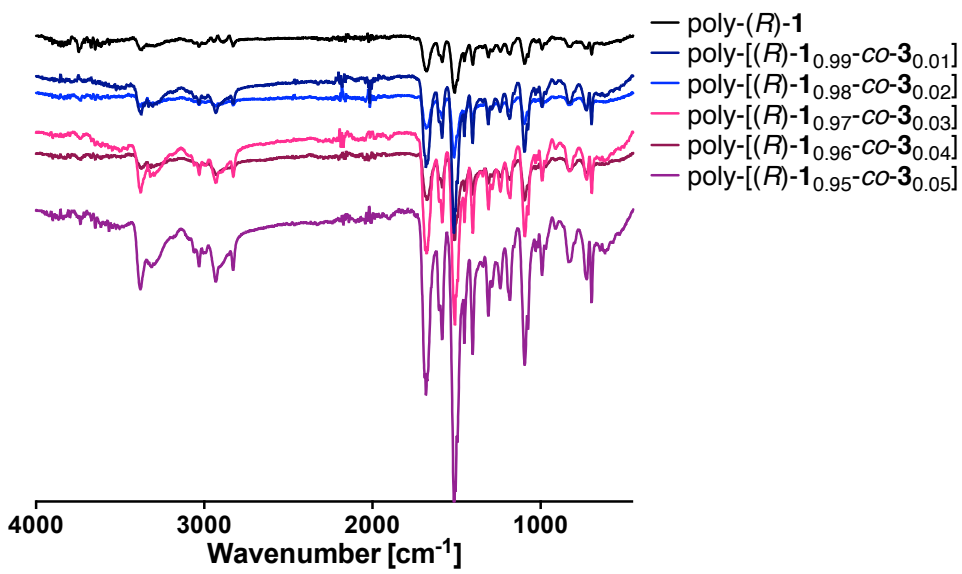

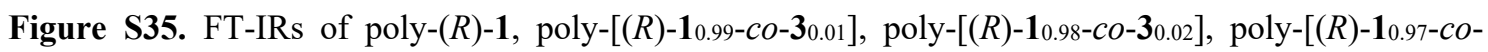

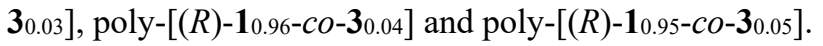

The cis stereoregularity of the copolymers was determined by ${ }^{1} \mathrm{H}$ NMR where the vinyl proton resonances appears at $5.7 \mathrm{ppm}$.

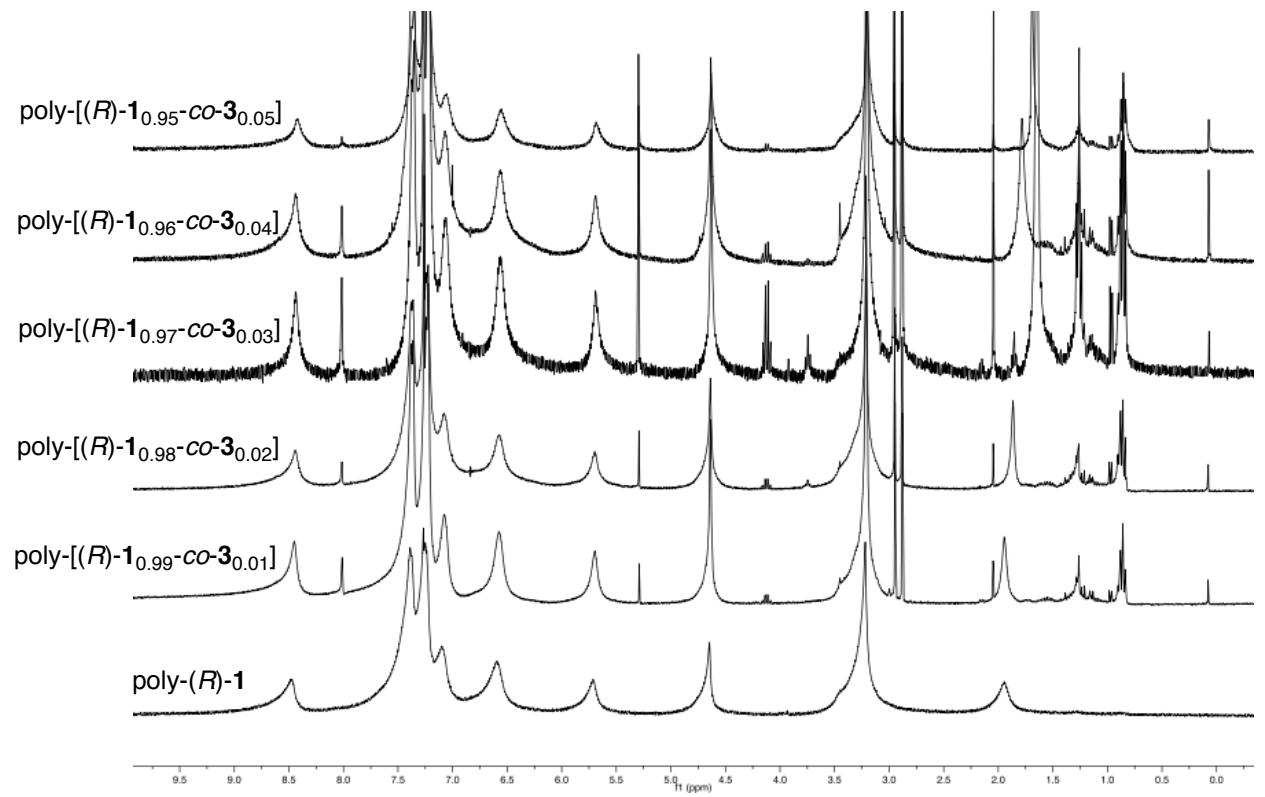

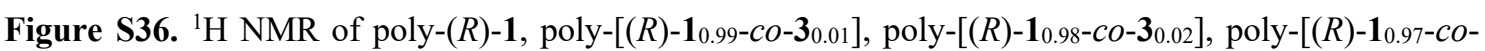
$\left.\mathbf{3}_{0.03}\right]$, poly-[(R)-1 $\left.0.96-c o-\mathbf{3}_{0.04}\right]$, poly- $\left[(R)-\mathbf{1}_{0.95}-c o-\mathbf{3}_{0.05}\right]$ in $\mathrm{CDCl}_{3}$. 

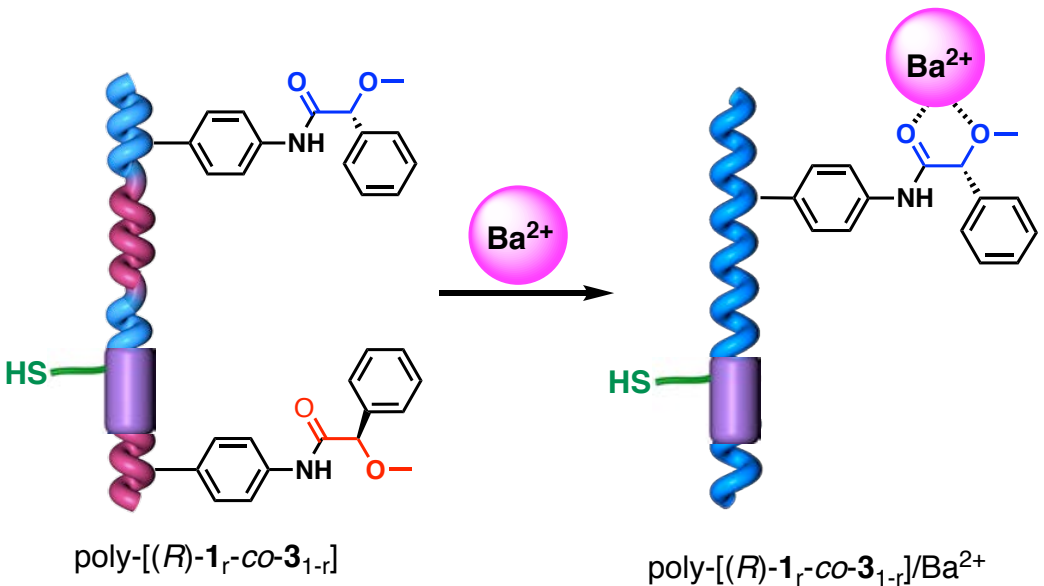

poly-[(R)-1 $\left.\mathbf{r}^{-C O-3_{1-\mathrm{r}}}\right] / \mathrm{Ba}^{2+}$

CD studies were performed with a solution of poly-[(R)-1 $\left.\mathbf{1}_{\mathrm{r}}-c o-\mathbf{3}_{1-\mathrm{r}}\right](\mathrm{r}=0.01-0.05)$ in $\mathrm{CHCl}_{3}(0.3$ $\left.\mathrm{mg} \mathrm{mL} \mathrm{mL}^{-1}\right)$ using $\mathrm{Ba}\left(\mathrm{ClO}_{4}\right)_{2}$ dissolved in $\mathrm{MeOH}$ which concentration was $10.0 \mathrm{mg} \mathrm{mL}^{-1}$.

Thus, poly- $\left[(R)-\mathbf{1}_{\mathrm{r}}-\mathrm{co}-\mathbf{3}_{1-\mathrm{r}}\right]$ dissolved in $\mathrm{CHCl}_{3}$ shows a null Cotton Effect $\left(\mathrm{CD}_{380}=0\right)$. The addition of $\mathrm{Ba}^{2+}$ ions to poly- $\left[(R)-\mathbf{1}_{\mathrm{r}}-c o-\mathbf{3}_{1-\mathrm{r}}\right]$ promotes the stabilization of $s p$ conformation between carbonyl and methoxy groups lead to $P$ helices.

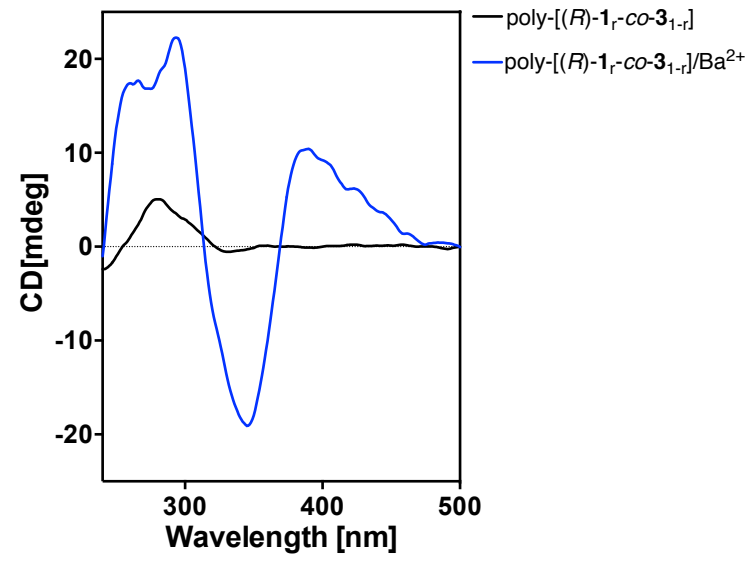

Figure S37. Representative CD studies of poly-[(R)-1 $\left.\mathbf{1}_{\mathbf{r}}-c o-\mathbf{3}_{1-\mathrm{r}}\right]$ in presence of $\mathrm{Ba}\left(\mathrm{ClO}_{4}\right)_{2}$. 


\subsection{Preparation of poly-[(R)-1 1 -co-3 $1-\mathrm{r}]-\mathrm{AgNPs}$}

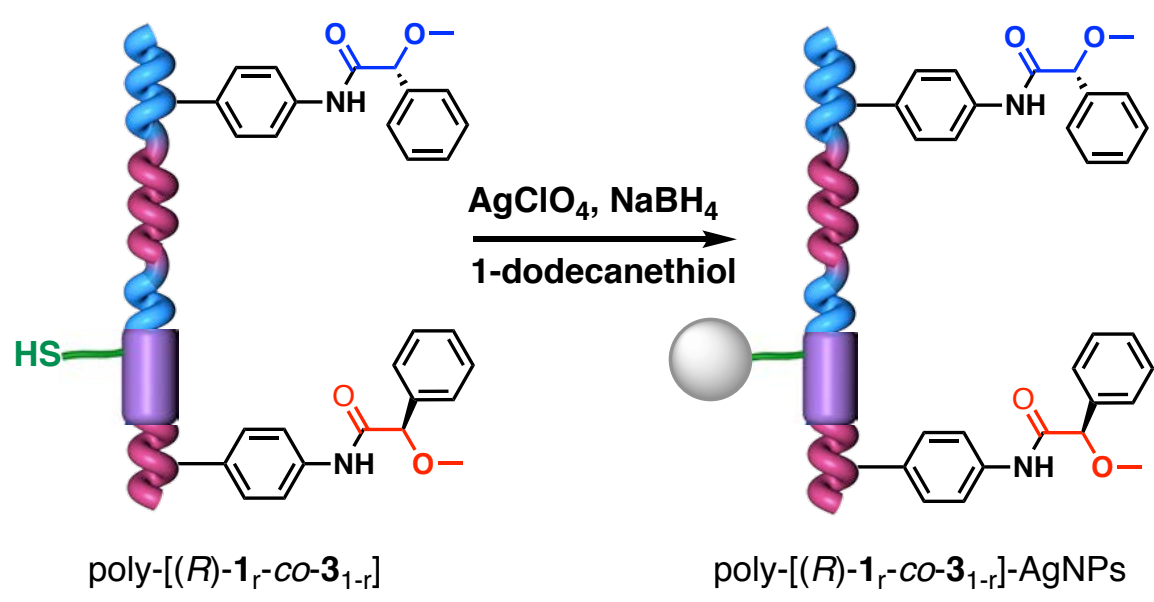

To a solution of tetraoctylamonium bromide (TOAB, $0.444 \mathrm{~g}, 0.812 \mathrm{mmol})$ into DCM $(20 \mathrm{~mL})$ was added a solution of $\mathrm{AgClO}_{4}(0.041 \mathrm{~g}, 0.202 \mathrm{mmol})$ in distilled water $(1.25 \mathrm{~mL})$ and allowed to stir at rt. After some time the mixture was washed with DCM (20 mL x 3). A copolymer (poly- $\left[(R)-\mathbf{1}_{\mathrm{r}^{-}}-C O-\mathbf{3}_{1-\mathrm{r}}\right)$ solution $(0.020 \mathrm{~g})$ in DCM $(5 \mathrm{~mL})$ and another solution of dodecanethiol $(40 \mu \mathrm{L})$ in DCM $(5 \mathrm{~mL})$ were prepared, both solutions were added simultaneously to the reaction mixture and allowed to stir at $-4^{\circ} \mathrm{C}$ for $30 \mathrm{~min}$. After this time was added as a reducing agent, a solution of $\mathrm{NaBH}_{4}(0.076 \mathrm{mg})$ in distilled water $(2 \mathrm{~mL})$. The reaction mixture turns a yellow-orange to brown - black. EtOH (HPLC grade, $50 \mathrm{~mL}$ ) is added to the solution and left at $-4{ }^{\circ} \mathrm{C}$ for $18 \mathrm{~h}$. After this time, the reaction mixture was filtered using a filter plate. The precipitate obtained was dissolved in $\mathrm{CHCl}_{3}$ and a second process was conducted in toluene precipitation using centrifuge $(1 \mathrm{~h}, 11000 \mathrm{rpm})$ and obtaining poly- $\left[(R)-\mathbf{1}_{\mathrm{r}^{-}}\right.$ $\left.c o-3_{1-r}\right]-A g N P$. The product was characterized by CD, UV, IR and STEM.

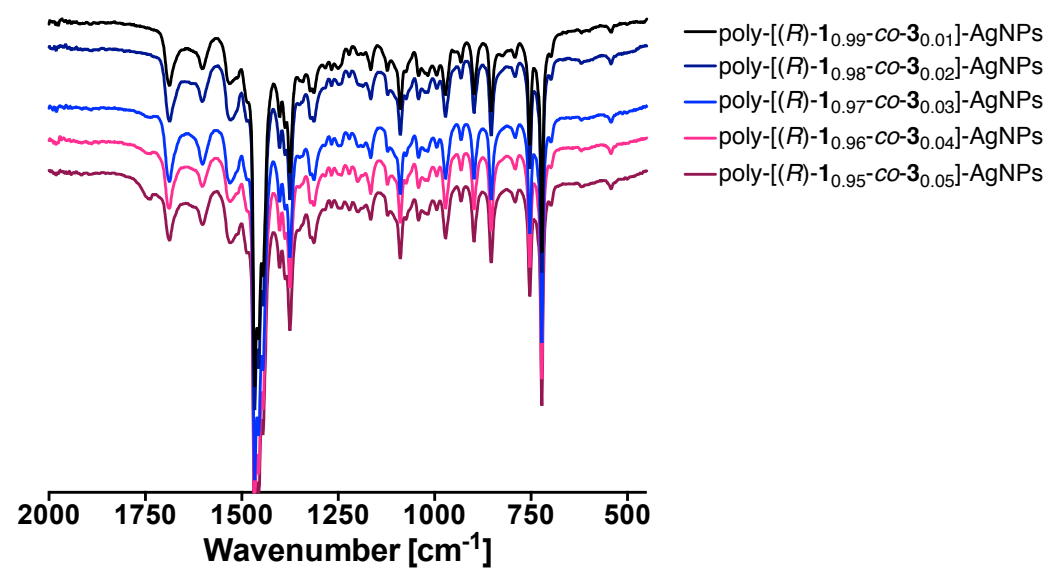

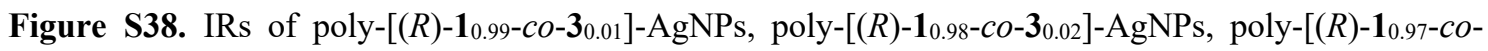
$\left.\mathbf{3}_{0.03}\right]$-AgNPs, poly-[(R)-1 $\left.{ }_{0.96}-c o-\mathbf{3}_{0.04}\right]-\mathrm{AgNPs}$ and poly- $\left[(R)-\mathbf{1}_{0.95}-c o-\mathbf{3}_{0.05}\right]-\mathrm{AgNPs}$. 

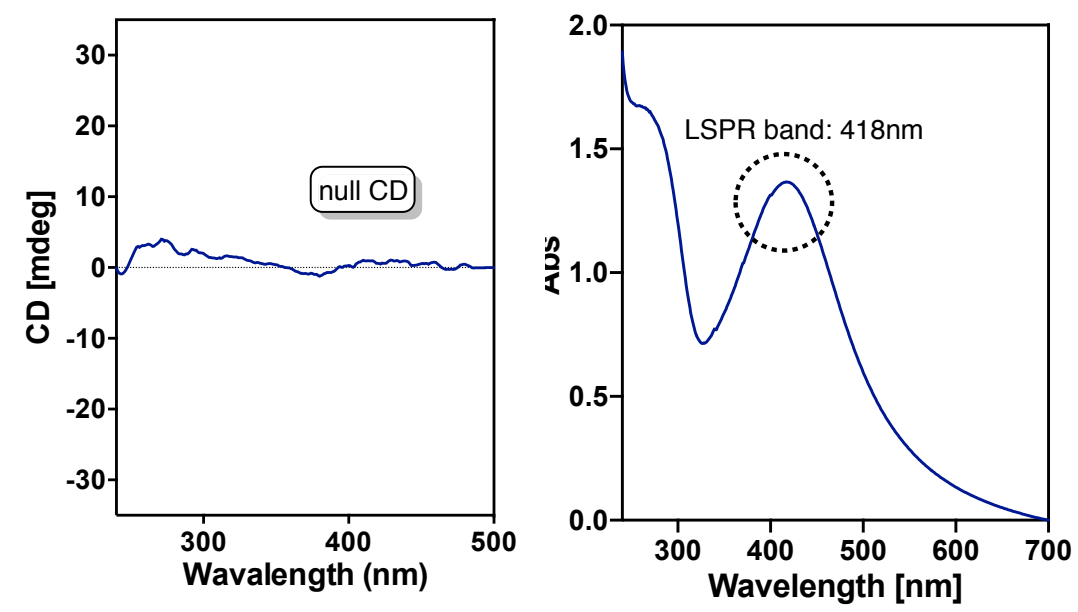

Figure S39. CD and UV-Vis studies of poly-[(R)-1 $\left.\mathbf{1}_{\mathbf{r}}-c o-\mathbf{3}_{1-\mathrm{r}}\right]-\mathrm{AgNPs}$.
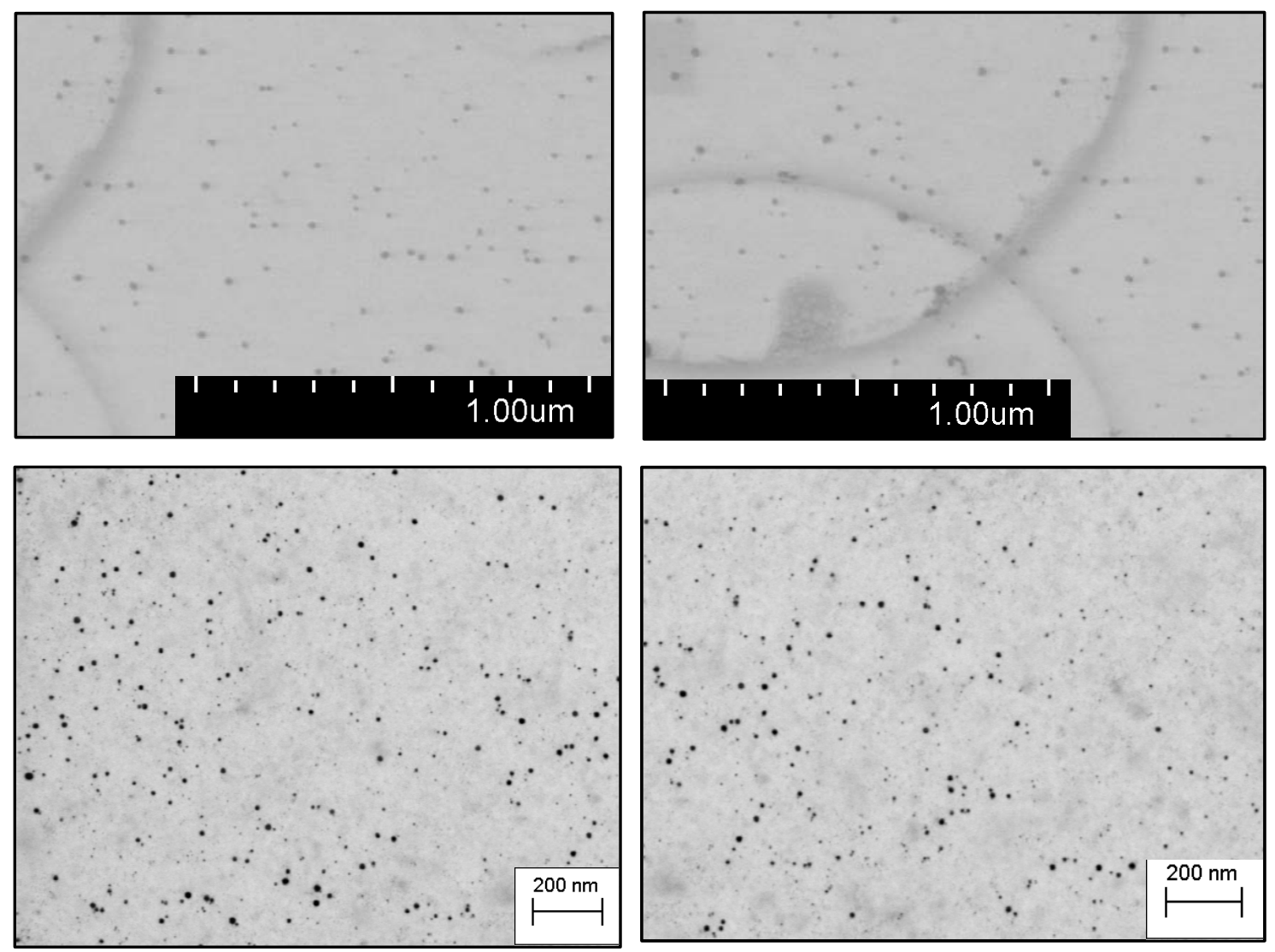

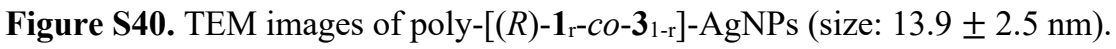




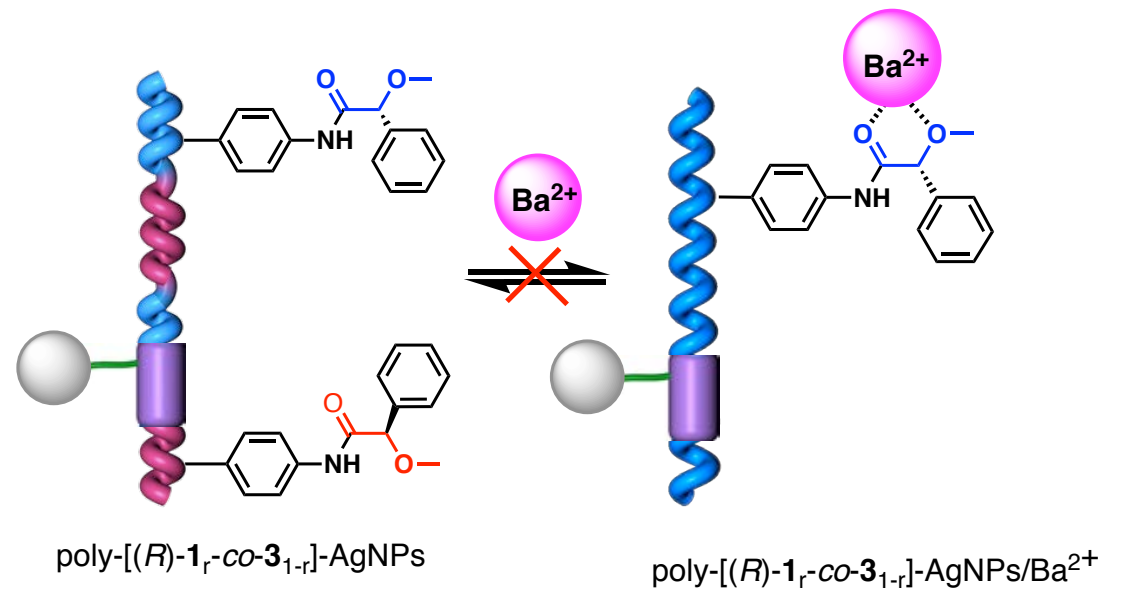

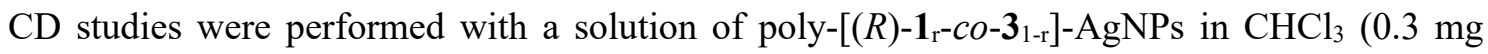
$\left.\mathrm{mL}^{-1}\right)$ using $\mathrm{Ba}\left(\mathrm{ClO}_{4}\right)_{2}$ dissolved in $\mathrm{MeOH}$ which concentration was $10.0 \mathrm{mg} \mathrm{mL}^{-1}$.

Thus, poly- $\left[(R) \mathbf{1}_{\mathrm{r}}-\mathrm{Co}-\mathbf{3}_{1-\mathrm{r}}\right]-\mathrm{AgNPs}$ dissolved in $\mathrm{CHCl}_{3}$ shows a null Cotton Effect $\left(\mathrm{CD}_{380}=0\right)$.

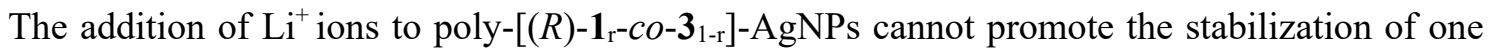
preferred helical sense.
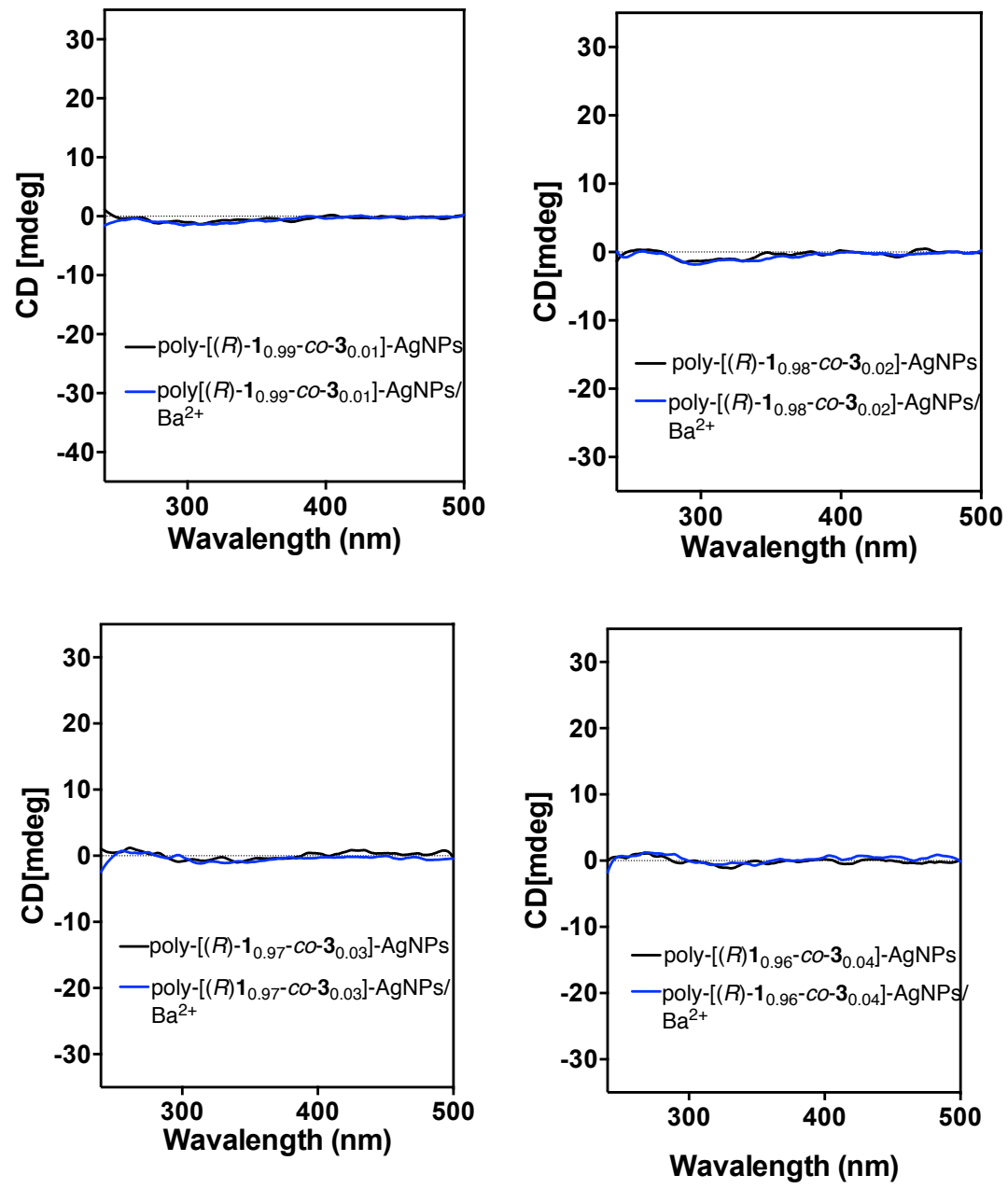


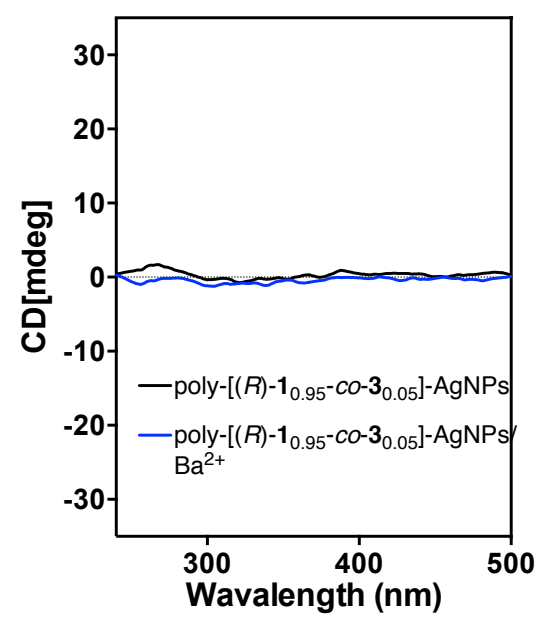

Figure S41. CD studies of poly-[(R)-1 $\left.\mathbf{1}_{\mathrm{r}}-c o-\mathbf{2}_{1-\mathrm{r}}\right]-\mathrm{AgNPs}(\mathrm{r}=0.01-0.05)$ in presence of $\mathrm{Ba}\left(\mathrm{ClO}_{4}\right)_{2}$.

\section{Chiral enhancement and reversibility of the process with resins metal scavengers in presence of silver nanoparticles}

To carry out these experiments, the resins were swollen in $\mathrm{CHCl}_{3}$ for $1 \mathrm{~h}\left(0.05 \mathrm{~g} \mathrm{~mL}^{-1}\right)$. Next, $100 \mathrm{mg}$ of resin were added to a solution of poly- $(R)-1-\operatorname{AgNPs} / \mathrm{Na}^{+}\left(0.3 \mathrm{mg} \mathrm{mL}{ }^{-1}\right.$ in $\mathrm{CHCl}_{3}$ ). After $30 \mathrm{~min}$, the $\mathrm{CD}$ and $\mathrm{UV}-\mathrm{Vis}$ spectra were recorded confirming that $\mathrm{Na}^{+}$ions are removed obtaining a null $\mathrm{CD}$.

Next, 0.5 equiv of $\mathrm{AgClO}_{4}\left(10 \mathrm{mg} \mathrm{mL}^{-1}, \mathrm{MeOH}\right)$ or 0.5 equiv of $\left(\mathrm{BaClO}_{4}\right)_{2}\left(10 \mathrm{mg} \mathrm{mL}^{-1}\right.$, $\mathrm{MeOH})$ were added to poly-(R)-1-AgNPs showing a chiral enhancement to $M$ or $P$ helices respectively.

Examples of the use of scavenger follow next: 


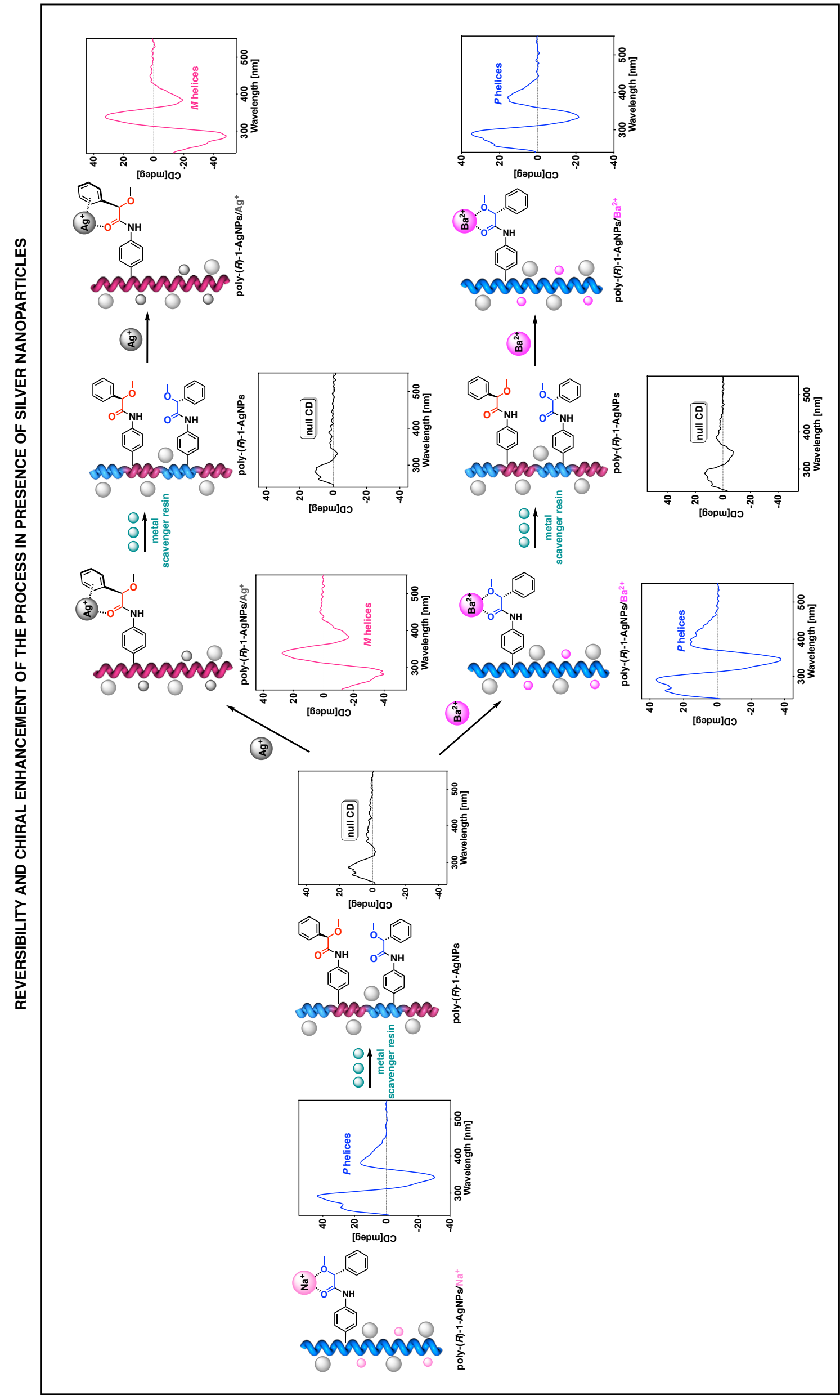




\section{Supporting references}

[S1] Freire. F; Seco, J. M.; Quiñoá, E.; Riguera, R.; Chiral Amplification and Helical Sense Tuning by Mono and Divalent Metals on Dynamic Helical Polymers, Angew. Chem. Int. Ed., 2011, 50, 11692-11696.

[S2] Leiras, S.; Freire, F.; Seco, J. M.; Quiñoá, E.; Riguera, R. Controlled modulation of the helical sense and the elongation of poly(phenylacetylene)s by polar and donor effect. Chem. Sci., 2013, 4, 2735-2743.

[S3] Arias, S.; Freire, F.; Quiñoá, E.; Riguera, R.; The leading role of cation- $\pi$ interactions in polymer chemistry: the control of the helical sense in solution, Polym. Chem., 2015, 6, 47254733.

[S4] Freire. F; Seco, J. M.; Quiñoá, E.; Riguera, R.; Nanospheres with Tunable Size and Chirality from Helical Polymer-Metal Complexes, J. Am. Chem. Soc., 2012, 134, 1937419383.

[S5] Bergueiro, J.; Núñez-Martínez, M.; Arias, S.; Freire, F.; Quiñoá, E.; Riguera, R.; Chiral Gold-PPA Nanocomposites with Tunable Helical Sense and Morphology, Nanoscale Horiz., 2020, $5,495-500$. 